\title{
Laboratory acoustic emission study for earthquake generation process
}

\author{
Xinglin Lei $\cdot$ Shengli Ma
}

Received: 8 August 2014/ Accepted: 15 November 2014/Published online: 5 December 2014

(C) The Author(s) 2014. This article is published with open access at Springerlink.com

\begin{abstract}
Since the similarity in size distribution of earthquakes and acoustic emissions (AE) was found in the 1960s, many laboratory studies have been motivated by the need to provide tools for the prediction of mining failures and natural earthquakes. This paper aims, on the one hand, to draw an outline of laboratory $\mathrm{AE}$ studies in the last 50 years, which have addressed seismological problems. Topics include the power laws in which the similarity between AEs and earthquakes is involved and progress that has been made in AE technology and laboratory AE study. On the other hand, this study will highlight some key issues intensively discussed, especially in the last three decades, such as aspects related to the pre-failure damage evolution, fault nucleation and growth in brittle rocks and discuss factors governing these processes.
\end{abstract}

Keywords Acoustic emission (AE) - Pre-failure damage · Rock fracture $\cdot$ Earthquake $\cdot$ Fault nucleation $\cdot$ Process zone

\footnotetext{
X. Lei $(\square)$

Geological Survey of Japan, National Institute of Advanced Industrial Science and Technology (AIST), Central 7,

1-1-1 Higashi, Tsukuba, Ibaraki 305-8567, Japan

e-mail: xinglin-lei@aist.go.jp

X. Lei $\cdot$ S. Ma

State Key Laboratory of Earthquake Dynamics, Institute of Geology, China Earthquake Administration, Beijing 100029, China

e-mail: mas1@ies.ac.cn
}

\section{Introduction}

Acoustic emission (AE) is an elastic wave radiated by rapid cracking in solids. As a technology of nondestructive inspection, $\mathrm{AE}$ has a long history of development and has been applied in numerous areas including material sciences, medical sciences and engineering fields. In Earth science, AE studies in mines were motivated by a desire to estimate in situ stress and to predict mining disasters resulting from rock failures. However, we will limit the scope of this paper to a narrow field of study in which $\mathrm{AE}$ is used, either as a tool or as a simulation model of an earthquake, to address problems relating to earthquake processes. In particular, we will concentrate our focus on the consequences of the pre-failure damage evolution, and fault nucleation and growth.

The Earth's crust comprises cracks and other heterogeneities at all scales from grain scale to plate scale. Such heterogeneities are characterised by fractal self-similarity or hierarchical structures (e.g. Ouillon et al. 1996; Lei et al. 1992). As a result, the fractures in the crust are somehow governed by the heterogeneities they involve. A fracture of any given size involves fractures of all scales less than it; therefore, the fracturing process must be investigated at all scales (Kagan and Jackson 1991). That is the key point in enabling laboratory studies to shed some lights on earthquake seismology. Information from pre-failure damage, which is monitored through $\mathrm{AE}$, may provide knowledge for understanding the nucleation of faulting. As we know, fault nucleation processes directly relate to the possibility of short-term earthquake prediction. The well-known Gutenberg-Richter (GR) relation (Gutenberg and Richter 1954), which describes a power-law scaling between earthquake size and number characterised by the so-called $b$-value, has been a recognised property of earthquakes for 
over 60 years. Several years after the finding, it was found that the same law holds true for AEs in stressed rock samples (Mogi 1962; Scholz 1968a). Mogi (1962) also observed that $\mathrm{AE}$ activity and $b$-value are related to rock heterogeneity: that is, a higher degree of heterogeneity means more AEs and a larger $b$-value. A more interesting point is that the $b$-value of an $\mathrm{AE}$ was found to decrease with increasing stress (Scholz 1968a). Promoted by these precedent studies, there has been a considerable amount of laboratory work in which $\mathrm{AE}$ is considered as an analogue of earthquake. By now, the $\mathrm{AE}$ technique has proven to be an excellent diagnostic tool for clarifying fracture processes (Lockner et al. 1991; Zang et al. 2000; Lei et al. 2000b; Young and Collins 2001; Fortin et al. 2006, 2009).

The present paper aims, on the one hand, to draw an outline of laboratory AE studies that address seismological problems. On the other hand, it aims to highlight some key issues intensively discussed in the last three decades. We begin with a brief outline of progress that has been made in $\mathrm{AE}$ technology and laboratory AE study. We then present several power laws in which the similarities between $\mathrm{AE}$ and earthquakes are involved. These laws are frequently referred to throughout this paper. Section 4 is the main content of this article, in which we summarise aspects relating to pre-failure damage evolution, fault nucleation and growth in brittle rocks, and discuss factors governing these processes. We specially focus on studies on the fracture of rocks having optimally oriented planar structures, which could be treated as a better analogue model of natural earthquakes. Finally, we discuss questions that remain poorly understood and issues of interest for future works. For reading convenience, each section is relatively independent but there are some crosslinks among different sections.

\section{Progress in AE technology and laboratory AE study}

\subsection{AE as an analogue model of earthquakes}

Earthquakes in the crust are caused by the rapid shear fracture of a fault. Thus, understanding the source processes of earthquakes relies on the understanding of shear fracturing in rocks. Abundant experimental evidence shows that macroscopic shear fracturing within rocks and other brittle materials does not occur by the growth of a single shear crack in its own plane. Rather, it is preceded by a very complex pervasive evolution of some pre-failure damage (e.g. Cox and Scholz 1988; Lockner et al. 1991; Lei et al. 2004). Therefore, both fracture dynamics and prefailure damage are a subject of interest in seismology (e.g. Diodati et al. 2000; Ponomarev et al. 1997). The fracturing dynamics and damage evolution in stressed materials were extensively studied in the laboratory by a number of methods including (1) the direct observation of samples by scanning electron microscopy (e.g. Zhao 1998) or optical microscopy (Wong 1985; Cox and Scholz 1988) operated during or after a fracture test, and (2) monitoring of the spatiotemporal distribution of AE events caused by microcracking activity (e.g. Lockner et al. 1991; Lei et al. 1992), which is the so-called AE technique. Fracturing dynamics and the pre-failure damage can be inferred from $\mathrm{AE}$ statistics as the number of $\mathrm{AE}$ events is proportional to the number of growing cracks, and the $\mathrm{AE}$ amplitudes are proportional to the length of crack growth increments in the rock (e.g. Main et al. 1989, 1993; Sun et al. 1991). Therefore, the $\mathrm{AE}$ technique is applied to the analysis of the micro-cracking activity inside the sample space, and it can be performed under an artificially controlled pressure, which is very important for the simulation of underground conditions.

Owing to the fact that earthquakes in the crust and $\mathrm{AE}$ events in stressed rocks show mechanical and statistical similarities in a wide range of aspects, $\mathrm{AE}$ in rocks are studied as a model of natural earthquakes (e.g. Ponomarev et al. 1997; Lockner et al. 1991; Lockner 1993; Main et al. 1993; Lei et al. 2000b, 2004, Lei and Satoh 2007; Zang et al. 2000; Thompson et al. 2005, 2006, 2009). The similarities between earthquakes and AEs are involved in a number of power laws: in temporal distribution (Lockner et al. 1991; Hirata 1987; Lei 2003; Ojala et al. 2004), in spatial distribution (e.g. Hirata et al. 1987; Lei et al. 1992), size distribution (e.g. Mogi 1962), and so on. For a long time, there has been a scale gap between laboratory studies and earthquake seismology. However, this gap has been overcome by recent developments in studies on mininginduced seismicity in deep mines (Kwiatek et al. 2010). It is discussed here that laboratory results can be applied directly to the Earth to represent local fault behaviour with no scaling requirement (Rice and Cocco 2007). We can now draw a full-scale diagram for rock fracture (Fig. 1).

The disadvantage of the $\mathrm{AE}$ technique is that it is insensitive to ductile deformation, which does not produce appreciable AE. Therefore, it is applicable only in brittle regimes.

\subsection{Progress in AE technology}

During the last five decades, a great number of laboratory studies were done following developments in experimental technology, AE monitoring technology and data processing methodology. It is beyond the scope of this article to make a thorough review of the history of AE technology, but it is helpful to draw a brief outline of some key points.

Fifty years ago, only the hitting time (time at which the signal amplitude reaches a pre-defined threshold) of an $\mathrm{AE}$ 
Rock fracture at different scales

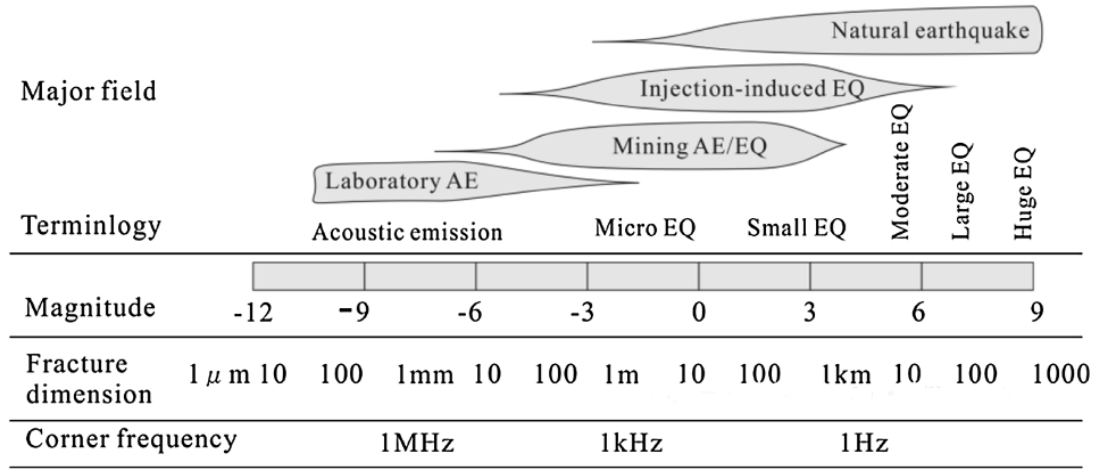

Fig. 1 Schematic diagram showing key aspects and parameters associated with rock fracture at different scales. Where EQ is shorthand for earthquake

could be recorded with a single sensor or a small number of sensors. The rock fracture test was performed under simple loading conditions.

Later, the number of sensors that could be used in a study increased and thus allowed the determination of the hypocentre of an AE. Developments in transient memory technique in the 1970s through to the 1980s led to the ability to make a digital multichannel recording of the full waveform of an AE. Hypocentre location was improved greatly by the use of more precise arrival times obtained through waveform analysis. In addition, it became possible to determine the mode of fracture, i.e. the focal mechanism solution of an AE source.

In the present day, $\mathrm{AE}$ are usually monitored by 16-32 sensors with digital waveform recording at up to a $200 \mathrm{MHz}$ sampling rate and up to a 16 bit A/D resolution. The dead time of a recording is sufficiently short and continuous recording is possible by use of very large amounts of memory. The waveform of most events can be captured with multiple channels, even for the period of dynamic failure in which the AE rate may reach several thousand a second. Rock fracture experiments can be performed under triaxial compression conditions with controlled fluid injection and pore pressure (Lei et al. 2011; Mayr et al. 2011). AE hypocentres are determined with a location error of a few mms (Lei et al. 2000a, b; Stanchits et al. 2006; Benson et al. 2007). A focal mechanism solution can be determined for individual events or a group of events (e.g. Lei et al. 2000b; Manthei 2005). As demonstrated by very recent studies (Goebel et al. 2012; Lei et al. 2013), progress in laboratory AE study is shedding more and more light on earthquake seismology.

\subsection{An overview of laboratory AE study}

In early studies, the GR relation and the relationships between AE activity and failure strength, inelastic strain and loading speed were examined and well documented (e.g. Mogi 1962; Scholz 1968a, b, c; Ohnaka and Mogi 1981, 1982; Sano et al. 1981, 1982) (see Sect. 3.1 for details). Sano et al. (1981, 1982) found that the failure strength and $\mathrm{AE}$ rate increased with the power of loading rate (strain) while inelastic strain decreased with increasing loading rate. By keeping the inelastic strain constant, Sano et al. (1982) found that $b$-value is a function of inelastic strain rate rather than stress level. The effects of inelastic strain rate could be enhanced by increasing pressure and using a wet sample (Masuda et al. 1987, 1988).

Through creep test, following the initiation of deformation, the event occurrence rate of $\mathrm{AE}$ bursts can be represented by the Omori type power law of aftershocks, which was originally recognised for earthquakes (Hirata 1987) (see 3.2 for details). Nishizawa and Noro (1990) used a self-exciting model to examine the interaction of preceding events with later ones and found that the interaction time, which specifies the length of the tail of the exciting function, tended to increase with advancing deformation.

Source location has been an important issue from the very beginning (Mogi 1968; Scholz 1968b). However, limited by AE monitoring technique, only a small number of events could be located. Byerlee and Lockner (1977) developed a six-channel system to detect the arrival time, amplitude, and vibration direction of AE wave from PZT sensors mounted on a sample. With this system, the hypocentre of a large number of AEs could be determined (Byerlee and Lockner 1977; Lockner et al. 1991, 1992). Since then, following the spreading of transient memory with built in high-speed A/D converter, multi-channel waveform recording systems were developed and used for AE monitoring (Maeda 1979; Sondergerd and Estey 1981; Nishizawa et al. 1982; Kuwahara et al. 1985; Yanagidani et al. 1985). The gap before a larger AE event, treated as an analogue of the gap before an earthquake, was observed under uniaxial conditions (Kusunose et al. 1982a, b). The localisation of $\mathrm{AE}$ hypocentres in "homogeneous" rock 
samples was reported by a number of groups (Lockner and Byerlee 1980; Nishizawa et al. 1982; Yanagidani et al. 1985; Hirata et al. 1987; Lei et al. 1992). The term "homogeneous" indicates fine-grained rocks free of mesoscale heterogeneities. Localisation means the changing from random distribution to spatial clustering. In general, AE hypocentre distribution is fractal and localisation results in a decreasing fractal dimension (see Sect. 3.4 for details). AE hypocentres, obtained during the creep test of a granite sample under triaxial compression, show a decreasing fractal dimension (Hirata et al. 1987). Similar results were obtained in two granite samples of different grain sizes (Lei et al. 1992).

Multi-channel waveform data allowed the determination of focal mechanisms and sources parameters of $\mathrm{AE}$ from the polarisation of the first motions. It was not surprising that many AEs demonstrate a shear fracture mode, similar with earthquakes (Kusunose et al. 1982a, b; Sondergerd and Estey 1982; Nishizawa et al. 1984/1985; Kuwahara et al. 1985; Yanagidani et al. 1985; Satoh et al. 1986; Shamina 1987; Lei et al. 1992; Satoh et al. 2000; Stanchits et al. 2006; Sellers et al. 2003). More detailed analysis shows some events, in particular relatively larger ones, are characterised by the so-called "wing crack": a shear crack with small tensile tails at the ends (Lei et al. 2000b). Results of tests on andesite show that AEs at relatively low-stress levels were randomly distributed within the sample and dominated by a pore-closing mechanism. While AEs concentrated on the final shear plane (at high stress levels), demonstrate shear fracturing (Satoh et al. 1986). Under triaxial compression conditions, AEs in coarse-grained granite show a major mechanism of shear fracture in all stages (Lei et al. 1992; Satoh et al. 2000); while a change from tensile-dominate to shear-dominate fracture was observed in fine-grained granite under the same experimental conditions (Lei et al. 1992).

In this section, we have briefly outlined advances in $\mathrm{AE}$ technology and laboratory AE study. Most studies, especially recent ones, are somewhat integrated. Integrated analysis of multiple aspects could provide us new insights. For example, Lei et al. (1992) found that in two granites of different grain sizes, the volumetric strains are almost linearly correlated with the number of AEs. At the same time, the fine-grained sample shows volumetric strains seven times larger than the coarse-grained sample. This difference results from the fact that a fine-grained sample shows many more tensile cracks than a coarse-grained sample. As another example, a temporal V-type $b$-value changing pattern normally reflects spatially clustered AE activity (e.g. Lei et al. 2000b; Lei 2003), while scattered background AEs result in relatively higher $b$-values. In the following sections, most results come from multi-channel monitoring and integrated analysis of $\mathrm{AE}$ data.

\section{Power laws in AEs and earthquakes}

In order to explore the similarity between AEs and earthquakes, we will list major power laws in the following subsections. These laws are recognised properties of rock fracture through the full-scale range.

\subsection{Gutenberg and Richter relation}

The most well-known power law, which also works for AE events in rocks (e.g. Mogi 1962; Scholz 1968a, b, c; Lei 2003), should be the Gutenberg and Richter (GR) (1954) relation of earthquakes:

$\log _{10} N=a-b M$,

where $N$ is the number of events of magnitude $M$ or greater, and $a$ and $b$ are constants. In terms of seismic moment the GR relation is a power law: $N\left(M_{0}\right)=A M_{0}^{-2 b / 3}$, since the seismic moment $M_{0}$ is linked with moment magnitude $M_{\mathrm{w}}$ by following equation (Kanamori, 1977):

$M_{\mathrm{W}}=\frac{2}{3} \log _{10} M_{0}-10.7$ (unit of $\left.M_{0}: \mathrm{Nm}\right)$.

The parameter $b$, commonly referred to as the " $b$ value", is commonly close to 1.0 in seismically active regions, and the relationship above (Eq. 1) hold true for all magnitudes above a lower end cut-off magnitude due to the detecting ability of seismic stations or the existing of a fault breakdown zone.

Beginning with Mogi's work published in 1962, a lot of laboratory works have been motivated by the expectation that precursory changes in $b$-value could have resulted from stress change and thus could be used for earthquake prediction and failure prediction in mines. Indeed, laboratory studies of $\mathrm{AE}$ events have consistently shown a decrease in $b$-value with increasing stress during the deformation of intact samples (Lockner et al. 1991; Meredith et al. 1990; Lei 2006; Lei and Satoh 2007).

In order to link the variations in $b$-value to established physical mechanisms, some damage models were proposed which employ the constitutive laws of subcritical crack growth of crack populations with a fractal size distribution (e.g. Main et al. 1989, 1993; Sun et al. 1991; Lei 2006). Three kinds of typical granite of different grain size distributions, in all nine samples, were loaded to failure at different stress rates (Lei 2006; Moura et al. 2006). The $b$ value decreased with increasing stress and could be well modelled with the damage laws by assuming a grain sizedependent initial mean crack length (Lei 2006) (see Sect. 4.1 for more discussions). At the same time, the primary $b$-value was found to be a function of grain size, a finer grain size leading to a higher $b$-value. 
Beside stress, $b$-value is strongly dependent on rock properties. The following lists the most important factors (in order of their relative importance, most important first).

(1) The distribution of pre-existing crack lengths. This feature can be directly derived from the aforementioned damage laws. According to the damage laws, $b$-value ranges from 0.5 to 1.5 and are inversely correlated with the mean crack length. In most cases, the initial distribution of crack lengths within a given rock is related to the grain size distribution of the rock. Thus, fine-grained Westerly granite shows a $b$ value larger than coarse-grained Inada granite. Under stress, a growing mean crack length leads to a decreasing $b$-value (see Lei 2006, for details).

(2) Macroscopic structures such as joints, veins and foliations. In these cases, the orientation and the healing strength of the structure planes are key factors. A number of metamorphic basalt samples cored along different directions from a deep mine have been used for fracture tests under triaxial compression. The results show that samples of unfavourably oriented foliation and optimally oriented foliation shows a primary $b$-value of $\sim 1.5$ and $\sim 1.0$, respectively.

(3) Homogeneity and grain size. Homogeneous and finegrained sedimentary rocks generally show large primary $b$-value. For example, Berea sandstone shows a $b$-value of $\sim 1.5$ (Lei et al. 2011).

(4) Results of some strongly foliated metamorphic rocks shows that the $b$-vale (prior to the peak stress) depends on the orientation of the foliation structure: it is close to unit for samples having favourably oriented foliations and 1.3-1.5 for samples having unfavourably oriented foliations.

Recent results from jointed or foliated rocks have demonstrated a typical pattern in the change of $b$-value: a precursory drop (from 1.0-1.5 to $\sim 0.5$ ) in foreshocks and a consequent recovery (to 1 to $\sim 1.2$ ) in aftershocks (see later sections). Foreshocks underlie the fault nucleation phase that again strongly depends on rock properties and loading conditions. Due to the fact that $b$-value depends on a number of factors, a change of $b$-value could not simply be linked with stress change. The usefulness of $b$-value as an earthquake predictor remains an area of continued debate. See Sect. 4.1 for more discussion on this issue. In Sect. 4, we will present an integrated summary of major AE statistics by which the fracturing process can be divided into typical phases.

\subsection{Modified Omori's law}

Both AE (Hirata 1987; Lei et al. 2003; Ojala et al. 2004) and earthquake data follow the modified version of modified Omori's law proposed by Utsu (1961), an empirical power law of the time-to-failure $\left(t-t_{m}\right)$, for aftershock rate $R_{\mathrm{a}}$ :

$R_{\mathrm{a}}=K_{\mathrm{a}}\left(c_{\mathrm{a}}+t-t_{m}\right)^{-p}$,

where $c_{\mathrm{a}}, K_{\mathrm{a}}$, and $p$ are constants. The constant $c_{\mathrm{a}}$ is a characteristic time. The $p$ value modifies the decay rate and typically falls in the range from 0.6 to 2.5 with a global mean of $\sim 1$ for earthquake aftershock sequences (Utsu et al. 1995). The foreshock rate $R_{\mathrm{f}}$, before a main event obeys a similar power law of the time-to-failure rate $\left(t_{m}-t\right)$ :

$R_{\mathrm{f}}=K_{\mathrm{f}}\left(c_{\mathrm{f}}+t_{m}-t\right)^{-p^{\prime}}$.

Acoustic emission bursts during creep tests (Hirata 1987; Lockner and Byerlee 1977) and AE aftershock rates for slip events in sandstone show $p$ values in the range of 1-2 (Goebel et al. 2012). Both foreshocks and aftershocks associated with the fracture of major asperities in a jointed rock can be roughly modelled with $p$ and $p^{\prime}$ of 1.0 (Lei et al. 2003). Unlike laboratory AEs, in the case of natural earthquakes, due to the small number of foreshocks, a stack of many sequences is generally required to draw a clear foreshock model.

Many studies, particularly earlier ones, used just a single transducer and thus it is impossible to correct for the effect of attenuation and the radiation pattern of individual events. Figure 2 shows results of a system developed in the 1990s by which AE hypocentres were determined through analysis of waveforms from 32 sensors, while the size of the $\mathrm{AE}$ was determined from the maximum waveform amplitude of 2 artificially selected sensors. The overall features of changing $b$-value of $\mathrm{AE}$ detected from different sensors without any correction are very similar, but for individual time intervals, the difference could be quite large (Fig. 2). It is worth noting that when AEs are

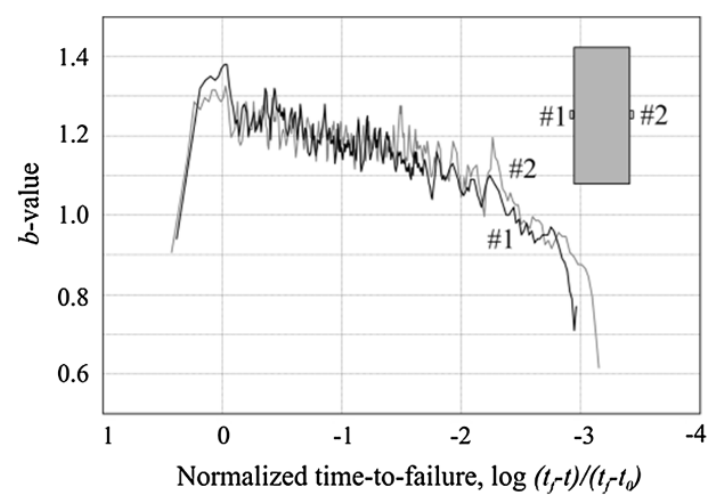

Fig. 2 Maximum likelihood $b$-values calculated from AE signals from two sensors are given as a function of the log of the normalized time-to-failure during a triaxial compression test of a fine-grained granite. The $b$-values were sequentially calculated for consecutive data sets of 1,000 events with an increment of 250 events. (Lei, 2006) 
clustered in the surface of a test sample, parameters estimated from a single sensor would be imprecise. Therefore, some temporal changes might reflect a change of spatial clustering.

\subsection{Critical point behaviour and dragon-kings}

Fractal or hierarchical complexities in fractures and heterogeneities of the crust, together with the non-linear interaction between earthquakes or AEs, leads to chaotic behaviour. Therefore, the concept of critical point behaviour has been applied to earthquakes, rock-bursts and AEs using time-to-failure analysis (Yamashita and Knopoff 1989; Sornette and Sornette 1990; Yu et al. 2004); where the catastrophic event is considered a critical phenomenon occurring at a second-order phase transition in an analogy with percolation phenomena. In the vicinity of the critical point, the variations in the energy release can be characterised by a power law of time-to-failure interspersed with log-periodic oscillations (Laherrere and Sornette 1998). Mathematically, such oscillations correspond to adding an imaginary part to the exponent of the power law (Moura et al. 2006):

$\sum E(t)=A+B\left(t_{\mathrm{f}}-t\right)^{\alpha+\mathrm{i} \omega}$,

where $E$ may be any kind of energy release rate, $t_{\mathrm{f}}$ is the failure time, $A$ is cumulative energy release at $t=t_{f}, B$ is negative, $\alpha$ and $\omega$ are constant. The log-periodic oscillations, resulting from the heterogeneities in the system, correspond to an accelerating frequency modulation as the critical time is approached. By fitting experimental data into Eq. (5), Moura et al. (2005, 2006) suggested that the imaginary part of the complex exponent $\omega$ has good correlation with grain size and loading rate. Larger grain size and faster loading rate result in a greater $\omega$, which indicates a longer interaction range in space. By ignoring the oscillations in Eq. (5) we get the power law of the accelerated moment release (AMR).

$\sum E(t)=A+B\left(t_{\mathrm{f}}-t\right)^{m}$.

As expected from Eq. 6, progressively increasing $\mathrm{AE}$ activity before the catastrophic failure of brittle rocks is commonly observed (Main et al. 1989, 1993; Main and Meredith 1991; Lei 2006) and can be represented by the AMR model with an $m$ of $0.2-0.3$, which is in agreement with the typical value for natural earthquakes (Yin et al. 2004; Lei and Satoh 2007; Wang et al. 2008).

AMR can be also derived from damage laws of crack population with a fractal size distribution (Lei 2006). Under loading conditions of constant stress rate $w$, the energy release rate $\dot{E}$ evaluated by the measured $\mathrm{AE}$ magnitude can be derived from laboratory-derived constitutive laws of the stress-induced subcritical growth of crack populations with a fractal size distribution (Lei 2006):

$\frac{\dot{E}(t)}{\dot{E}(t=0)}=\left(1-\frac{t}{t_{\mathrm{f}}}\right)^{\frac{l+2-2 l^{\prime}}{2-l}}(1+w t)^{l}$,

where $l$ is referred to as the stress corrosion index (the exponent of the power law between the mean quasi-static rupture velocity of crack populations and the stress intensity factor (Main et al. 1993), $l^{\prime}$ is the exponent of the power law between the mean quasi-static rupture velocity of crack populations and $\mathrm{AE}$ rate, the failure time $t_{\mathrm{f}}$ is defined so that $c$ approaches infinity. Under constant stress (creep) condition $(w=0)$, Eq. (7) reduces to:

$\frac{\dot{E}(t)}{\dot{E}(0)}=\left(1-\frac{t}{t_{\mathrm{f}}}\right)^{-m^{\prime}}, \quad m^{\prime}=\frac{l+2-2 l^{\prime}}{2-l}$.

The cumulative energy release is then obtained by integrating (7) with time:

$$
\begin{gathered}
\sum E=\int \dot{E} \mathrm{~d} t=A+B\left(t_{\mathrm{f}}-t\right)^{m}, \\
B=-\frac{1}{\left(1-m^{\prime}\right) t_{\mathrm{f}}}, \quad m=1-m^{\prime} .
\end{gathered}
$$

Equation (9) is the same as Eq. (6). The exponent in the power law of AMR is thus linked with the exponents of another two power laws relating $\mathrm{AE}$ rate and mean crack length. In such a consideration, both event rate and moment release increase as a power of time-to-failure. The AMR is the result of a cascade of small events progressively releasing stress before a large event.

Having described the power laws, it is appropriate to mention the existence of dragon-kings; that is, extreme events of a magnitude which do not follow the GutenbergRichter power law governing the size distribution of other events. For a well-developed fault, the largest repeated earthquake (termed characteristic earthquake) is likely to be a dragon-king event. The ultimate failure of the sample, or fracture of major asperities on the fault surface (Fig. 3), normally leads to extreme events, i.e. dragon-kings. These events have a magnitude significantly greater than that expected by the GR power-law relation between the magnitude-frequency distribution for either foreshocks or aftershocks. There are at least two mechanisms that may lead to dragon-kings: (1) the power-law event rate and moment release increasing and (2) hierarchical fracturing behaviour resulting from hierarchical inhomogeneities in the sample (Lei 2012). In the first mechanism, the final failure corresponds to the end-point of the progressive occurrence of events, or in other words AMR, and thus the resulting dragon-king event can be interpreted as a superposition of many small events. In the second mechanism, an event of 


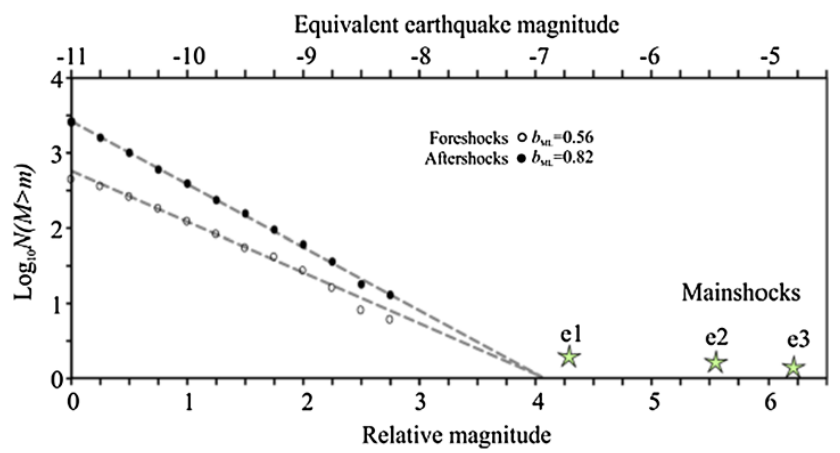

Fig. 3 Magnitude-frequency distribution of fore- and after shocks associated with fracture of a major asperity on a fault going to failure. The e1 $\sim 3$ mark the main events which are termed as "dragonkings," extreme events departed from the power law (Lei, 2012)

extreme size is the result of fracture growth stepping from a lower hierarchy into a higher hierarchy on a fault surface having asperities characterised by hierarchical distribution (of size or strength) rather than simple fractal distribution. In both mechanisms, the underlying physics is that fracture in rocks is hard to stop beyond certain threshold.

\subsection{Fractal distribution of AE hypocentres}

Similar to earthquakes, the spatial distribution of AEs also shows fractal self-similarity (e.g. Hirata et al. 1987; Lei et al. 1992). The generalized correlation-integral (Kurths and Herzel 1987), was usually applied for multi-fractal analysis of the spatial clustering of AEs and earthquakes:

$$
\begin{gathered}
C_{q}(r)=\frac{1}{N}\left[\sum_{j=1}^{N}\left(\frac{N_{j}(R \leq r)}{N-1}\right)^{q-1}\right]^{\frac{1}{(q-1)}}, \\
(q=-\infty, \ldots,-1,0,1, \ldots, \infty),
\end{gathered}
$$

where $N_{j}(R<r)$ is the number of hypocenter pairs separated by a distance equal to or less than $r, q$ is an integer, and $N$ is the total number of $\mathrm{AE}$ events analysed. If the hypocenter distribution exhibits a power law for any $q$, $C_{q}(r) \propto r^{D_{q}}$, the hypocenter population can be considered to be multi-fractal, and $D_{q}$ defines the fractal dimension that can be determined by the least-squares fit on a log-log plot. In the case of a homogeneous fractal, $D_{q}$ does not vary with $q$. It can be easily proved that $D_{0}, D_{1}$ and $D_{2}$ coincide with the information, capacity and correlation dimensions, respectively.

Localization of AE activity leads to a decrease of fractal dimension, thus it was expected to be a possible indication of approaching failure. Gradual decreasing $D$ was observed in some cases but not in others cases (Hirata 1987; Lei et al. 1992; Lei and Satoh 2007). By looking up results obtained so far, especially recent ones utilising high-speed recording, we can draw some clearer conclusions now (see
Sect. 4 for details). In general, there is no gradual localization as expected. The final fracturing nucleated in a site with no clear correlation with the previous damage. The chance to observe decreasing $D$ depends on the number of foreshocks which is somewhat determined by the critical size of the fault nucleation zone (over which the rock fails dynamically) as well as the growing velocity of the fault. In cases of a small nucleation zone or fast growing velocity, a smaller number of foreshocks are insufficient to cause a notable change in $D$.

In this section, we have summarized major power laws with key points showing the similarity between AEs and earthquakes. It is worth noting that the similarity is also seen in many other aspects such as focal mechanism solutions, the scaling relation between moment and corner frequency, fault nucleation processes, and so on. Some aspects will be discussed in later sections.

\section{Pre-failure damage, fault nucleation and growth}

\subsection{Typical phases of AEs during rock deformation and fracture}

It is noted by many authors that the fracturing of rocks in laboratory experiments demonstrates some typical stages with different underlying physics corresponding to the stress level or deformation history. For example, creep tests normally show three deformation stages: primary, transient and accelerated. Since the number of AEs is well correlated with volumetric strains (e.g. Lei et al. 1992) and inelastic strains (e.g. Mogi 1962; Scholz 1968a, b, c; Sano et al. 1981, 1982), AE activity directly reflects rock deformation and thus show corresponding phases. Detailed analysis of AEs is helpful for investigating the physics underlying each phase of deformation.

Through an integrated analysis of several AE statistics obtained from AE data collected with the high-speed AE waveform recording system, a three-phase pre-failuredamage model has been proposed by Lei et al. (2004) and further enforced with new data (Lei 2006; Lei and Satoh 2007; Rao et al. 2011). The lithology of the test samples covers granitic, sedimentary, and metamorphic rocks while the structure of the samples covers fine- and coarsegrained, jointed and foliated. Time-dependent statistics include the energy release rate, $b$-value of the magnitudefrequency distribution and fractal dimension and/or spatial correlation length (SCL) of AE hypocentres. The data from these studies indicate that the pre-failure damage process is characterised by three major phases of micro-cracking activity, termed the primary, secondary and nucleation phases, respectively. Figure 4 shows a typical example in which all phases with a large number of AEs and the 
features of every phase are very clear (Lei 2006). In some cases, AEs during the dynamic fracturing process and following aftershock period could be recorded (e.g. Main et al. 1992; Thompson et al. 2006; Lei et al. 2013). A general summary of the phases follows.
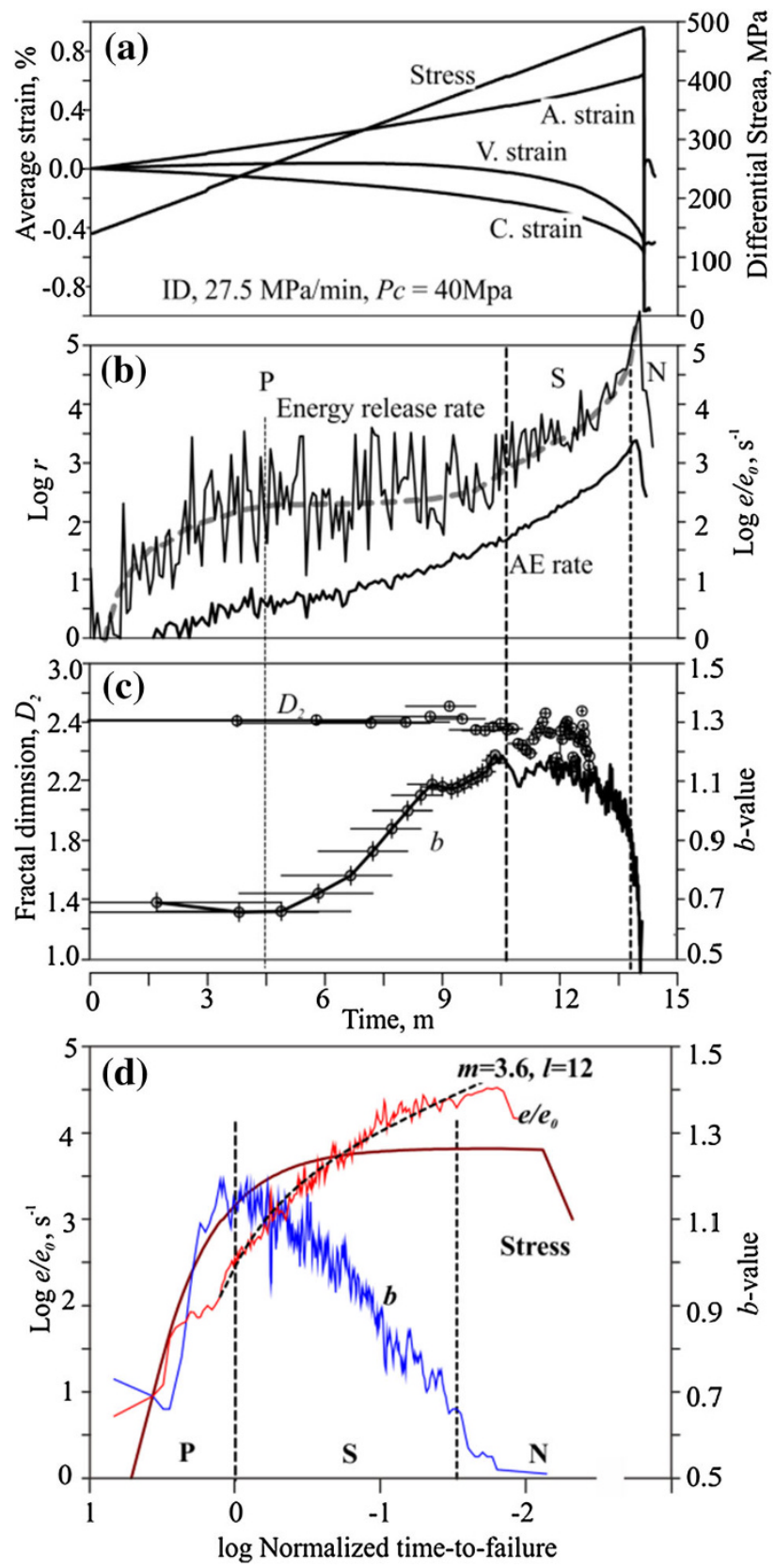

Fig. 4 An example of AE data obtained from a typical experiment on a coarse-grained Inada granite sample under constant stress rate (27.5 MPa/min). Differential stress, average axial/circumferential/ volumetric strains (a); $\mathrm{AE}$ energy release rate and event rate calculated consecutively every $10 \mathrm{~s}$. (b); $b$-value and fractal dimension $D_{2}(\mathbf{c})$; are plotted against time. Stress, energy rate and $b$-value against normalized time-to-failure in logarithm coordinate (d). P, S, and $\mathrm{N}$ denote the primary, secondary and nucleation phases, respectively. The $\mathrm{m}$ and 1 are parameters defined in Eqs. 6, 7 and 8 . (Modified from Lei 2006)

\subsubsection{Primary phase}

The primary phase reflects the initial opening or ruptures of pre-existing microcracks, and it is characterised by an increase, with increasing stress, of both the event rate and the $b$-value. The rate of AE depends on the density of preexisting cracks. The observed fact of initially low and subsequently increasing $b$-value suggests that relatively longer cracks likely rupture at relatively lower stress.

\subsubsection{Secondary phase}

The secondary phase involves the sub-critical growth of a crack population, revealed by an increase, with increasing stress, in the energy release rate and a decrease in the $b$-value.

\subsubsection{Nucleation phase}

The nucleation phase corresponds to the quasi-static fault nucleation processes. During the nucleation phase, the $b$ value decreases rapidly down to the global minimum value, in well-monitored cases, it is around 0.5. See Sect. 4.2 for further aspects on fault nucleation.

\subsubsection{Dynamic phase}

For most intact rocks, it is impossible to distinguish individual $\mathrm{AE}$ events during the dynamic fracturing period since many events occur in a short time, resulting in background noise (Thompson et al. 2006; Benson et al. 2007; Schubnel et al. 2007; Thompson et al. 2009; Lei 2012). In some cases, with fewer foreshocks, the main shock could be recorded and located (see an example in Fig. 5).

\subsubsection{Aftershock phase}

In well-jacked samples and samples of optimally oriented weak surfaces (foliated-, joint-, healed-fault and so on), aftershocks could be recorded. Similar to earthquakes, aftershocks are concentrated in the fault plane and show a gradual recovering of $b$-value.

\subsubsection{Stick-slip phase}

In well-jacked samples, a few numbers of stick-slip events could be monitored with AE data (Thompson et al. 2009).

For the secondary and the nucleation phases, $b$-value and release rate can be modelled as functions of the time-to-failure (Sects. 3.1, 3.3) and thus can be treated as an indicator of the critical point (Lei and Satoh 2007). Both the failure of a major asperity on the fault plane and the catastrophic failures of the rock samples are generally preceded by (1) accelerated energy release, (2) a decrease in fractal dimension and SCL with a 

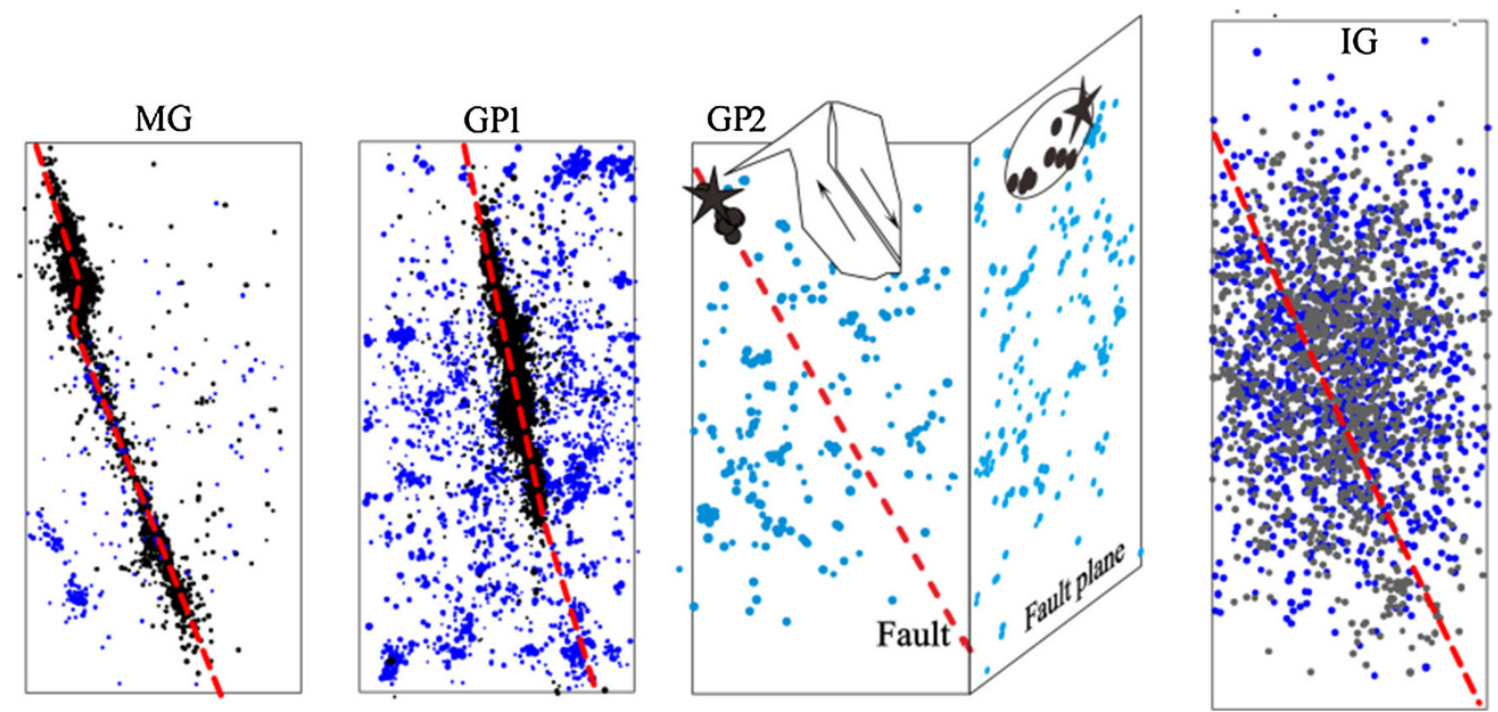

Fig. 5 AE hypocenters in granite rocks. Grey and blue circles indicate AE hypocenters in the pre-nucleation phase. Black circles indicate foreshocks in the nucleation phase. (Modified from (Lei 2006, and Lei et al. 2000a)

subsequent precursory increase indicating growth of fault nucleation and (3) a decrease in $b$-value from $\sim 1.5$ to $\sim 0.5$ for fine-grained rocks, and from $\sim 1.1$ to $\sim 0.8$ for coarsegrained or weak rocks such as S-C cataclasite. However, each parameter also reveals more complicated temporal evolution due to either the heterogeneity of the rock (see Sect. 3.3) or the micro-mechanics of shear fracturing (see Sect. 4.5). AE statistics in the secondary and nucleation phases confirm the potential importance of integrated analysis of two or more parameters for successfully predicting the critical point. The decreasing $b$-value and increasing energy release may prove meaningful for intermediate-term prediction, while the precursory increase in fractal dimension and SCL are possible indications of approaching failure and can facilitate shortterm prediction.

Lithology, density and size distribution of pre-existing cracks, mesoscale and macro-scale heterogeneities all have an overall role in AEs. There are some cases in which some phases are not clear. In general, homogeneous (both finegrained and coarse-grained) rocks with pre-existing cracks likely show all phases. Heterogeneous or weak rocks such S-C cataclasite normally show a lack of the primary phase. Samples with few pre-existing cracks and samples containing optimally oriented weak structures, likely show an unpredictable fracturing behaviour as well as a lack of primary and secondary phases, in addition the nucleation phase has a small number of AEs.

\subsection{Fault nucleation}

Earlier AE waveform recording systems could record a few tens of events per second, insufficient for exploring the details of fault nucleation which corresponds to an $\mathrm{AE}$ rate on the order up to several thousand events per second. Indeed, the final fracture plane could be mapped with prefailure AEs in inhomogeneous samples having weak structures (Lockner and Byerlee 1980; Satoh et al. 1990, 1996; Lockner et al. 1992). If the test sample contains optimally oriented weak surfaces, and if the environmental rigidity is sufficient high to sustain the quasi-static growth of fault nucleation, the fault could be nucleated at quite a low-stress level relative to the peak stress. On the other hand, in homogeneous and brittle rocks, fault nucleation is likely created at a stress close to the peak stress, while the environmental rigidity is lowered by damage throughout the sample volume the rock fails rapidly with a large stress drop (Lockner et al. 1992; Lockner 1993; Satoh et al. 1996). To overcome this difficulty, different approaches were applied among research groups.

In the U.S. Geological Survey, the AE occurrence rate rather than strain rate was used as a feedback signal to control the axial loading speed. With such a technique, the rapid faulting nucleation process could be stabilized and thus make it possible to observe the complete nucleation and quasi-static growth process of a fault through the analysis of AE hypocentres (Lockner et al. 1991, 1992). In the German Research Center for Geosciences (GFZ), a non-standard "asymmetric" loading was used to force shear faulting under uniaxial compression and earlier (and accordingly slowed down) faulting nucleation (Zang et al. 1998, 2000). In the Geological Survey of Japan (GSJ), a rapid AE monitoring system was developed in late 1990s (Lei et al. 2000b), which can record AE waveforms without major loss of events, even for $\mathrm{AE}$ event rates on the order 
of several thousand events per second, typical for fault nucleation in brittle rocks. Therefore, it is possible to study cracking activity during the spontaneous and quasi-static growth of a fault in intact rocks. The main advantage of the GSJ system over the AE feedback technique mentioned above is that the process of fault growth is in a condition of constant stress rate or constant stress (creep) loading, which allows both quasi-static and dynamic crack growth to occur. As we know the constitutive relation of friction (e.g. Dieterich 1992) and the mechanics of the interaction between cracks are indeed time-dependent so the fault growth under artificially slowed down conditions with time-varying strain rate may not be sufficiently representative of the dynamic loading condition in the Earth. Recent systems were utilized with large amounts of memory, allowing continuous waveform recording on multiple channels and more detailed analysis of faulting nucleation, dynamic fracturing and aftershock processes (Thompson et al. 2005, 2006; Stanchits et al. 2006; Benson et al. 2007; Lei 2012).

By using the AE feedback approach, the nucleation and quasi-static growth of faults in Westerly granite and sandstone were observed (Lockner et al. 1991, 1992). Results of Lockner et al. (1992) are comprehensive. In granite samples, prior to the peak stress, AE activity was distributed evenly throughout the samples. The fault plane nucleated abruptly at a point on the sample surface, and then grew across the sample, accompanied by a gradual drop in axial stress. AE locations showed that the fault propagation was guided by a fracture front, termed process zone. After the process zone, a damage zone was created with AE activity of a low level. In sandstone samples, a diffuse damage zone appeared prior to peak strength and gradually localised into an incipient fault plane. It is interesting that after passing through peak stress, the shear fault plane grew in a way similar to that in the granite samples. Migration of AE hypocentres shows that the fault growth is not smooth but that there are periods of acceleration and deceleration. Such a kind of fault nucleation process was also observed using X-ray $\mathrm{CT}$ to view the damage created in rock samples which have been exposed to triaxial compression under constant strain (in a circumferential direction) rate and released at different stages of post-peak stress (Kawakata et al. 1997). In the experiments of Zang et al. (2000), the propagation velocity of the process zone is varied from $2 \mathrm{~mm} / \mathrm{s}$ to $2 \mu \mathrm{m} / \mathrm{s}$ using either displacement or the rate of acoustic emissions to control the applied axial force. Comprehensive results are (1) the width of the process zone is $\sim 9$ times the grain diameter inferred from acoustic data but is only 2 times the grain size from optical crack inspection; (2) the process zone of fast propagating fractures is wider than for slow ones; (3) the density of microcracks and acoustic emissions increases approaching the main fracture; (4) shear displacement scales linearly with fracture length; and (5) the ratio of the process zone width to the fault length in Aue granite ranges from 0.01 to 0.1 inferred from crack data and acoustic emissions, respectively. With a combination of $\mathrm{AE}$ feedback and continuous waveform recording, accelerating propagation speed of fault nucleation from $\sim 1 \mathrm{~mm} / \mathrm{s}$ to a few hundreds $\mathrm{m} / \mathrm{s}$ could be fingered out through 3D AE locations (Thompson et al. 2006).

The use of a high-speed waveform recording system in the GSJ laboratory is successfully in monitoring AE hypocentres during spontaneous fault nucleation and even the unstable failure process in intact brittle rocks under constant stress (rate) loading conditions. A number of different kinds of samples including intact rocks (Lei et al. 2000a, b), jointed rocks with unbroken asperities (Lei 2003), shale with thin quartz veins (Lei et al. 2000c) and foliated rocks (Lei et al. 2013), were investigated (see Sects. 4.3, 4.4, 4.5, 4.6) and more detailed structures of faulting nucleation and process zone were obtained (see Sect. 4.5).

\subsection{Factors governing AE activity and fault nucleation processes}

\subsubsection{Role of mesoscale/macroscopic heterogeneities}

Many works likely select homogeneous samples for guaranteeing reproducibility. Results from carefully selected samples containing mesoscale and macroscopic heterogeneities are also meaningful for investigating their role.

Satoh et al. (1996) observed the precursory localization and development of micro-fractures along the final fracture plane in an amphibolite under triaxial creep. Lei et al. (2004) presented results of samples containing an optimally oriented fault or optimally oriented bedding planes. Faults, either pre-existing or newly created during rock fracture test, in the bedded rock have a wide range of strength distribution. They observed that the fault nucleation processes are strongly governed by heterogeneities. A long-term decreasing trend and short-term fluctuation of the $b$-value in the phase immediately preceding dynamic fracture are identified as characteristic features of the failure of heterogeneous faults. Figure 5 is a renewed plot with data gathered from several papers. In the plots, AE hypocentres are projected to a section perpendicular to the fault surface. MG sample is a coarse-grained granite containing a fault with relatively homogeneous strength, but there is extensional jog (Jouniaux et al. 2001). GP1 contains a pre-existing and naturally healed fault of heterogeneous strength distribution. GP2 has strong asperities (the presence of the fault did not weaken the sample much). GP is a granite-porphyry of few pre-existing cracks (Lei et al. 2000a). As a comparison, a coarse-grained Inada 
granite (IG) sample is added. MG and GP1 show a clear nucleation phase with intense AE activity. GP2 has only a few foreshocks, which map a nucleation zone of $10 \mathrm{~mm} \times 20 \mathrm{~mm}$. IG shows numerous pre-nucleation AEs, but the nucleation phase could not be verified.

\subsubsection{Role of foliation, bedding and anisotropic structures}

Foliation in metamorphic rocks and bedding structures in sediments are special heterogeneities of systematic orientation and may lead to strong anisotropy in the rock. Lei et al. (2000c) presented some interesting results from shale containing a few thin quartz veins. The bedding plane was optimally oriented for shear under stress conditions. As a result, the fault was created along a bedding plane and cut the veins. Fault segments along the bedding plane showed slip behaviour with large compressive deformation before the peak stress, while the vein asperities showed large precursor dilatancy prior to dynamic rupture accompanied with bursts of AEs.

In a recent work, a series of samples of foliated metamorphic basalt and metasediment from deep mines in Australia, cored along different directions with respect to the foliations, were tested under triaxial compression to examine the role of foliation in rock fractures (Villaescusa et al. 2009; Lei et al. 2013). It was found that the foliation in these rocks played a governing role in AEs at every stage of deformation. Figure 6 shows a comparison of AE hypocenters in two samples in which the foliation is either optimally or unfavourably oriented for shear rupture under the experimental loading conditions. Samples of optimally oriented foliations demonstrate a fracturing process that is somewhat similar to natural earthquakes, showing: (1) a small number of foreshocks, (2) a large number of aftershocks and (3) the fault nucleation zone is a small fraction of the fault dimension. Samples with unfavourably oriented (orientation parallel with $\sigma_{1}$ in the sample) foliations demonstrate more complicated fracturing processes and the final fracture is created through the linkage of damaged clusters along the shear zone. Every individual cluster shows a vertical extension along the foliations. Except for some earlier clusters, major clusters are aligned along the shear zone of the final fault showing a tensile en-echelon array (Fig. 6). The vertical AE clusters are clearly related with the vertical foliations. Figure 7 is a schematic plot showing key points of different cases. All aspects concerning the fracture including the geometry of the final fracture planes, the failure strength, pattern of pre-nucleation AEs and nucleation processes, are systematically affected by the foliation angle.

\subsubsection{Role of fluid}

In the laboratory, the governing role of pore pressure in pre-failure damage and final failure in either low-porosity rocks, such as granites (Byerlee and Lockner 1977; Kranz et al. 1990; Masuda et al. 1990), or high-porosity rocks, such as porous sandstones (Schubnel et al. 2007; Stanchits et al. 2009; Mayr et al. 2011), has been well established. Mayr et al. (2011) presented some interesting results in a porous sandstone of a permeability of $10^{-17}-10^{-16} \mathrm{~m}^{2}$. In their experiments, AEs could be triggered by a pore pressure increase over a critical pore pressure level. The critical level was controlled by the applied pore pressure of the previous cycle according to an apparent Kaiser effect in terms of pore pressure. This memory effect of the rock vanished if additional axial stress was applied to the sample before the next injection cycle. In addition, they found that in a highly fractured rock the nucleation of the final failure was more likely to be controlled by the propagation of the fracture than by the diffusion of pore pressure.

Dilatancy and dilatancy hardening are generally observed to occur prior to brittle faulting. Pore pressure decreases resulting from dilatancy are the most important mechanism of dilatancy hardening in a wet sample. Therefore, fluid flowing and in situ drainage conditions are dominant factors that govern rock fracture behaviours. Positive feedback between AE activity and pore pressure diffusion has been observed in the laboratory (Masuda et al. 1990). According to field evidence, an increase in fluid pressure may produce not only significant seismicity (e.g. Lei et al. 2008) but also stable or aseismic slips along pre-existing faults (Cornet et al. 1997).

In a recent work, Lei et al. (2011) found that drainage conditions play a governing role in deformation and fracture of Berea sandstone, which has a porosity of $\sim 20 \%$ and a permeability of $\sim 10^{-13} \mathrm{~m}^{2}$. The well-established dilatancyhardening effect can be greatly suppressed by dilatancy-driven fluid flowing under good drainage conditions. Fast diffusion of pore pressure leads to a significant reduction in rock strength and stabilisation of the dynamic rupture process. Furthermore, good drainage conditions have the potential to enlarge the nucleation dimension and duration, thereby improving the predictability of the final catastrophic failure.

In the study mentioned above, the speed of pore pressure diffusion is a key factor. Since pore pressure diffusion is inversely proportional to the viscosity of the fluid, fluids of lower viscosity are thus expected to be more efficient to suppress the dilatancy-hardening effect. Evidence was recently obtained through hydraulic fracturing laboratory experiments with supercritical (SC-) and liquid (L-) $\mathrm{CO}_{2}$, which have viscosity one order lower than water at low temperature (Ishida et al. 2012). Their results show that $\mathrm{AE}$ hypocenters with the $\mathrm{SC}$ - and $\mathrm{L}-\mathrm{CO}_{2}$ injections tend to distribute in a larger area than those with water injection, and furthermore, $\mathrm{SC}-\mathrm{CO}_{2}$ tended to generate cracks extending more three dimensionally (rather than along a flat plane) than $\mathrm{L}-\mathrm{CO}_{2}$. 

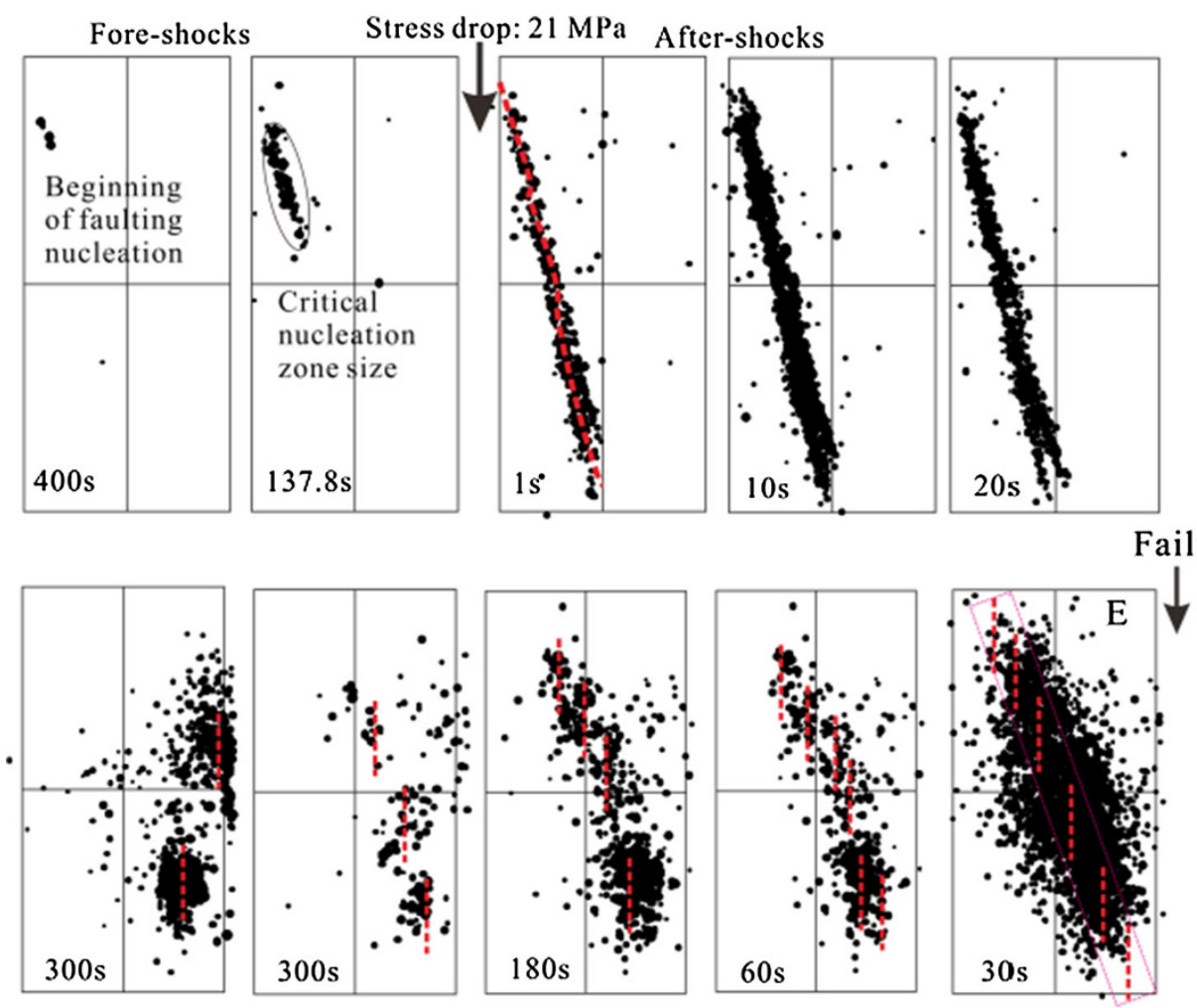

Fig. 6 A comparison of AE hypocentres obtained in a metamorphic basalt sample (upper) and a metasediment sample (lower). In the basalt sample, the weak foliation planes are optimally oriented for rupture under the experimental loading conditions. In the metasediment sample, the weak bedding planes are vertical and thus are badly oriented. The time interval of every plot is indicated in seconds. (Modified from Lei et al. 2013)

(a)

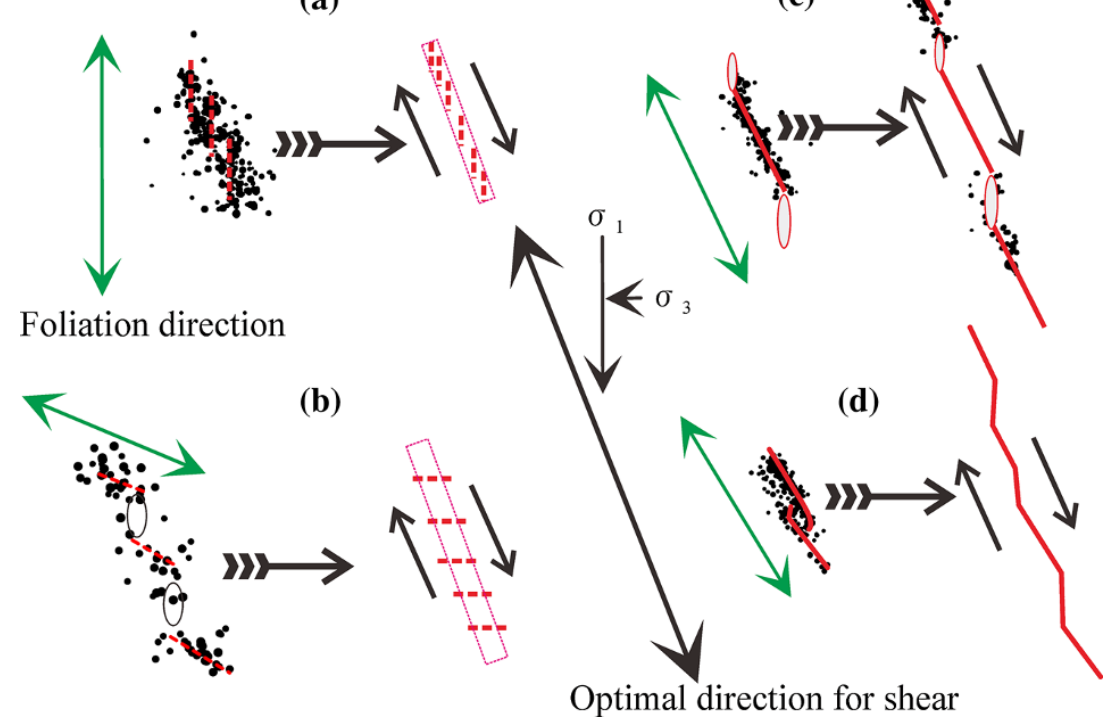

Fig. 7 Schematic plots show mesoscale patterns of AE hypocenters and fault mechanisms in foliated rocks of different foliation orientations (after Lei et al. 2013, see text for details) 
The role of fluids in rock fracturing is an interesting issue not only in earthquake seismology but also in industrial applications in which fluids are injected into the Earth (see Sect. 5.3 for further discussion).

\subsection{Fracture of optimally oriented planar structure:} a better simulation model of earthquakes

The aforementioned samples with optimally oriented planar structures are a better simulation model of earthquakes. Such works are of considerable interest and importance, because they could provide rules useful for understanding earthquake processes.

A detailed study by Lei and collogues (Lei 2003; Lei et al. 2003) on the fracture of a shear fault containing several unbroken asperities in a granitic porphyry reveals that a quasi-static nucleation of the shear faulting corresponds to the fracture of coupled asperities on the fault plane. Acoustic emissions caused by the fracture of individual asperities exhibit similar characteristics to the sequence for natural earthquakes, including foreshock, mainshock and aftershock events. Foreshocks, initiated at the edge of the asperity, occur with an event rate that increases according to a power law of the temporal distance to the mainshock, and with a decreasing $b$-value (decrease from $\sim 1.1$ to $\sim 0.5$ ). One or a few mainshocks then initiate at the edge of the asperity or in the front of the foreshocks. The aftershock period is characterized by a remarkable increase and subsequent gradual decrease in $b$-value and a decreasing event rate obeying the modified Omori's law. The fracture of neighbouring asperities is then initiated after the mainshock of a particular asperity. The progressive fracturing of multiple-coupled asperities during the nucleation of shear faulting results in short-term precursory fluctuations in both $b$-value and event rate, which may prove useful information in the prediction of failure of the main fault plane of seismic earthquakes.

In a very recent study, using the X-ray computer tomography (CT) technique and an $\mathrm{AE}$ monitoring approach, Goebel et al. (2012) found that geometric asperities identified in CT scan images were connected to regions of low $b$-values, increased event densities and moment release over multiple stick-slip cycles. This result is consistent with the aforementioned fracture of unbroken asperities on a naturally healed fault.

By summarising the results presented in Sects. 4.3.2, 4.3.3 and 4.3.4, we can conclude that the fault nucleation behaviour, including critical size, duration time, and $\mathrm{AE}$ productivity, depends on the heterogeneity of the area of weakness of the fault compared with that of the host rock. If the fault is as strong as the host rock then the fracture makes no difference and the rock remains intact. Furthermore, a homogeneous fault or rock mass appears to fracture in unpredictable ways without a consistent trend in precursory statistics, while inhomogeneous faults fracture with clear precursors related to the nature of the heterogeneity.

\subsection{Process zone}

It has been observed that, "unlike tensile cracks, shear fractures do not grow by simple propagation in their planes but show a complex breakdown process" (Scholz et al. 1993). The process zone is defined as the damage zone at the tip of a propagating fault. It is a very important aspect of fault mechanics and has been studied by field work (e.g. Engelder 1974; Granier 1985; Lloyd and Knipe 1991; Bjarnason et al. 1993; Chester et al. 1993; Vermilye and Scholz 1998) and laboratory work (Cox and Scholz 1988, 1998; Lei et al. 2000b; Zang et al. 2000). The process zone geometry and size, relative to the fault contained within it, can be used to evaluate fault growth models. The process zone may also play an important role in the permeability structure of fault zones. It has long been recognised that faults form major conduits for fluid flow (e.g. Sibson 1981; Kerrich 1986). Faults can also act as permeability barriers (Logan 1991; Blanpied et al. 1992; Sleep and Blanpied 1992; Chester et al. 1993). Scholz and Anders (1994) pointed out that this may be due to the contrasting roles of the cataclasite zone and process zone on fault permeability. Understanding process zones as a whole, as well as understanding the size, structure and orientation of elements within process zones, will lead to a better understanding of the role faults play in fluid migration within the Earth's crust.

It was observed that a fault initiated at a site with slight preceding damage and then propagated into un-faulted rock with a process zone of intense cracking (Reches and Lockner 1994). Reches and Lockner (1994) proposed a model based on the mutual enhancement of cracking due to stress induction and illustrated the propagation of a fault through the interaction of tensile cracks. However, based on knowledge of the focal mechanism type, Lei et al. (2000b) observed that tensile cracking was dominant only in the front area of the fault, i.e. within the process zone. When the density of the damage zone increased or when the fault growth was accelerated, shear mode or other modes containing a shear component became the major/ dominant modes of cracking; this is in agreement with a suggestion by Cox and Scholz (1988) based on microstructural examination.

Figure 8 shows a renewed fault model with major features illustrated. As shown in the figure, shear fault growth is guided by the progressive occurrence of tensile cracks in the process zone at the fault tip. By noting the optimal orientations of cracks in the process zone, it is easy to understand that a shear fault is likely to bend. At the same 


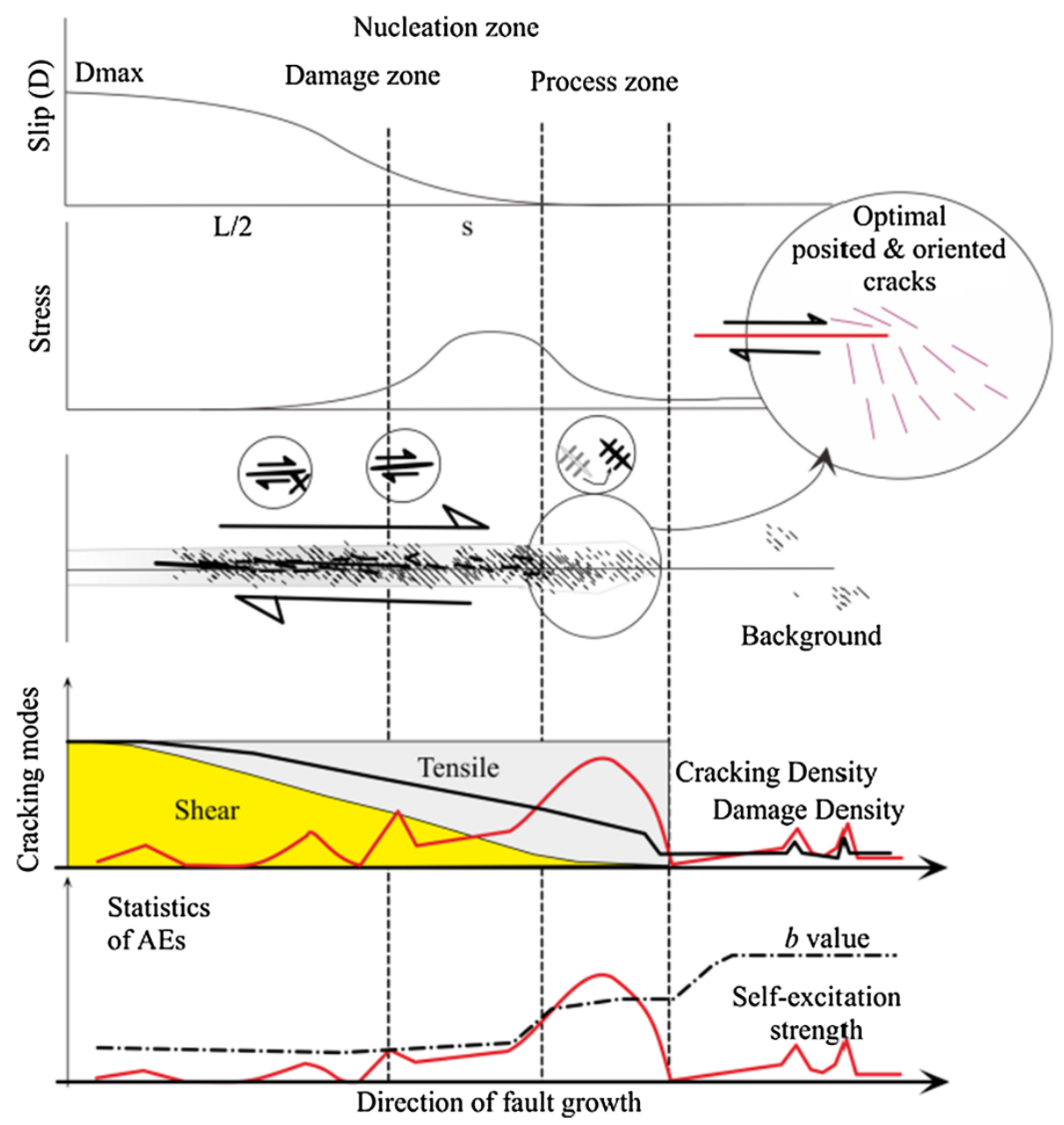

Fig. 8 Schematic section of a quasi-statically growing shear fault (modified from Lei et al. 2000b). The fault is growing towards the right. The fault consists of two portions: the process zone at the fault tip and the damage zone behind it. The AE activity in the process zone is dominated by tensile cracking, a $b$-value lower than the background, fewer larger events, and strong self-excitation. The damage zone is characterised by shear cracking, low $b$-value, larger events and weak self-excitation

time, the entire shear fault is driven to propagate along the optimal direction as defined by the Mohr-Coulomb failure criterion. As a result of such micro-mechanics and macromechanics, a shear fault is likely to show complicated processes such as temporal fluctuations (acceleration and deceleration) and spatial step-overs, as derived from $\mathrm{AE}$ monitoring (Lei et al. 2000b; Lei et al. 2013) and microstructural observations (Kawakata et al. 2000). The core of the shear fault is the cataclasite zone, which may form gouge layers after repeated slips and thus may reduce the permeability along the direction perpendicular to the fault. While at step-overs and fault ends, the remaining damage zone of tensile cracks may greatly enhance the permeability.

The Dugdale-Barenblatt model (Dugdale 1960; Barenblatt 1962), which incorporates elastic-plastic fracture mechanics, has the advantage of an analytical solution and is applied to faulting for the breakdown process (Cowie and Scholz 1992; Scholz et al. 1993). According to this model, several scaling laws are expected between fault lengths, the maximum slip, breakdown length $S$ and displacement $d o$ (c.f. Scholz et al. 1993).

\subsection{Acoustic emissions during fault stick-slip and stable sliding}

Experimental studies on fault stick-slip behaviour are motivated by the need to provide fault frictional models which are required for earthquake cycling simulation. $\mathrm{AE}$ events have been observed during frictional sliding on precut faults in laboratory rock samples. Some insights could be gained from AE monitoring. Beside the lithology of the blocks, the roughness of surface, geometries (bend, orientation) of the fault, gouge and loading speed are major 
factors have been investigated. A summary of the effects of these characteristics follows.

\subsubsection{Surface roughness}

The sliding surfaces were normally ground with abrasive of desired particle size. The characteristic scale of asperities on the sliding surfaces corresponds to this particle size (cf. Brown and Scholz 1985). Scholz et al. (1968) have monitored AE activity during stick-slip cycles in granite and found that no pattern can be seen between successive stick-slip cycles during a given experiment or between different experiments. A drop in the $b$-value of foreshocks before a stick-slip event was observed in a large granite sample containing a saw cut (Weeks et al. 1978). The AE sources were located on the pre-cut fault, and their focal mechanism solution was consistent with that expected theoretically for macroscopic sliding. It is not surprising that the roughness of the fault surface is a first order factor governing the fractional behaviour and AE activity. Frictional sliding experiments on coarse-grained Inada granite blocks in double shear show that: (1) smooth-ground $(600 \#, 10 \mu \mathrm{m})$ surfaces produce the maximum number of $\mathrm{AE}$ events and (2) $b$-values are related to the surface topographic fractal dimensions, i.e. smooth surfaces exhibit lower $b$-values than rough-ground $(\# 60,300 \mu \mathrm{m})$ surfaces (Sammonds and Ohnaka 1998). Thus, the change of $b$-value (decreasing from 1.5 to 1.0 , and from $\sim 1.2$ to 0.5 for rough and smooth surfaces, respectively) with accumulative amount of slip can be interpreted in terms of evolving fractal crack damage during frictional sliding of the fault surface. It was also suggested that the grain-scale topography determines the AE source dimension, while the fractal-domain asperities control the magnitude of the stress drop (Yabe 2008). The source radii of large AE events may reach the order of $10 \mathrm{~mm}$ (as derived from the widths of the first P-wave pulses). High-frequency $\mathrm{AE}$ signals during the passing rupture of a stick-slip event, observed by near fault AE monitoring, show similar source dimensions (Kato et al. 1994). A single AE event cannot be due to the rupture of a single asperity and is instead caused by coherent rupture of many asperities which have a spot size of contact on the order 10-100 $\mu \mathrm{m}$ (Yabe et al. 2003).

\subsubsection{Strain rate- and Slip-dependence}

Strain rate- and slip-dependent AE activity was confirmed by a number of experiments during the stable sliding of bare fault surfaces (e.g. Yabe et al. 2003). Acoustic emission per unit slip was found to decrease with increasing strain rate.

\subsubsection{Fault geometry}

For a slightly bent (5 degree) fault (600\#, ground $10 \mu \mathrm{m})$, AEs are likely to cluster in the bend; this is caused by cracks in the host rock rather than the rupture of asperities on the surface (Kato et al. 1999). The friction experiments on macroscopically non-homogeneous faults indicate that there exist two types of nucleation phase for stick-slip instability of non-homogeneous faults, which coincide with the pre-slip model and the cascade model, respectively (Ma et al. 2002). A very recent study of stick-slip test of saw cut fault (hand lapped with 600 grit abrasive) shows that each stick slip begins as an $\mathrm{AE}$ event that rapidly ( $\sim 20 \mu \mathrm{s})$ grows about 2 orders of magnitude in linear dimension and ruptures the entire of the simulated fault (150 mm length) in a seismic slip which weakens the fault and produces AEs that will eventually cascadeup to initiate the larger dynamic rupture (McLaskey and Lockner 2014).

\subsubsection{Gouge}

Mair et al. (2007) presented results on AE activity obtained during shear of granular layers. For a given loading strain rate, the AE rate decreased with accumulating slip. Step increases in strain rate led to immediate and sustained increases in AE rate; however, AE per unit slip decreased with increasing strain rate. The slip-dependent behaviours are consistent with those of bare surface experiments (Yabe et al. 2003). Single AE events generated in sheared granular materials require the coherent rupture of many grain contacts.

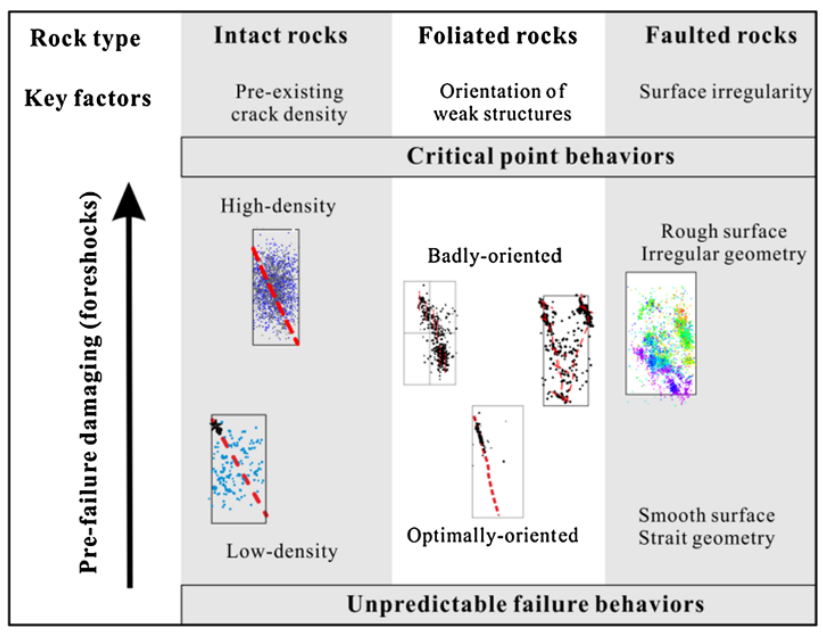

Fig. 9 Schematic plot show a summary of microcrack activity preceding rupture of different rock types and the key factors governing the pre-failure damaging processes 
In summary, Fig. 9 schematically shows microcrack activity preceding rupture of different rock types and the key factors governing the pre-failure damaging processes.

\section{Issues for study in the future}

Since the similarity between the size distribution of earthquakes and AEs has been documented (Mogi 1962; Scholz 1968a), more than 50 years has passed. Considerable numbers of studies have been carried out on $\mathrm{AE}$ activity before, during, and after the fracture of rocks. Together with other experimental studies, particularly those concerning the frictional behaviour of a fault, laboratory studies have shed light onto earthquake seismology. Rules obtained at the laboratory scale are helpful for understanding natural earthquakes on a significantly larger scale. However, we cannot simply bridge laboratory scale to a scale several orders larger. At every step up from a smaller scale to a larger scale, we encountered something different. The difference could be small for each step but, after many steps, we could see something quite different. Studies on all scales are important. With such considerations in mind, we can list some issues worth being addressed in future studies.

\subsection{Better analogue model of natural faults}

Thus far, it has been observed that a weak strength (relative to the host rock) optimally oriented planar structure shows fracturing behaviour underlined with several parallels with natural earthquakes. For example, asperity regions in lab and field studies are connected to spatial $b$-value anomalies, and such regions appear to play an important role in controlling the nucleation spots of dynamic slip events (Lei 2003; Goebel et al. 2012; McLaskey and Lockner 2014).

\subsection{Scale laws related with fault nucleation, process zone, and fault growth}

The process zone at the front of a propagating fault involves many important scaling laws (c.f. Scholz et al. 1993). It is a very interesting work to systematically examine these laws using the newest $\mathrm{AE}$ monitoring technology and better analogue models. An increase in process zone size with increasing fault length is also expected but is not yet proved.

\subsection{Role of fluid}

Pore fluid is a very important factor that must be properly addressed in order to understand the faulting behaviour of crustal rocks, particularly the nucleation process. In fault mechanics, the scenario of stability, dilatancy hardening and poor drainage has been argued since Rice (1983). This fault zone dilatancy theory is the result of the negative feedback between dilatancy hardening and slip-weakening during the mainshock fault movement. Lei et al. (2011) proposed a different scenario of stability with no dilatancy hardening and good drainage for the failure of intact porous rocks. Drained intact rock comes to be stable via a lowered strength that has been realised before the fault starts moving. The competing mechanism between dilatancy hardening and pore pressure diffusion is strongly dependent on local hydraulic conditions and thus may result in different fracturing behaviours. Thus, systematic experiments under various drainage conditions using various rocks of different hydraulic properties are required. Quantitative investigation of rock fracture through such experiments by means of $\mathrm{AE}$ techniques is an interesting issue for the future. On one hand, it may shed some light on earthquake seismology. On the other hand, it may provide a fundamental technical background promoting applications including: enhanced geothermal systems (EGS), extraction of shale gas and corebed gas and $\mathrm{CO}_{2}$ geological storage. The latter of which involves fluids being intensively pumped into the deep Earth under high pressure; injectioninduced earthquakes would be a problem that must be well addressed.

\subsection{Scientific challenges in earthquake prediction and control}

Given the similarities among sequences of natural earthquakes, mining-induced earthquakes, and laboratory AEs, studies have primarily aimed to identify precursors that could be used as prediction tools of rock failure in mines and earthquakes in crust (c.f. Lockner 1993).

Current earthquake prediction falls into two methodological groups based on their treatment of either the frictional behaviour of individual faults or rock fracture within the fault zone and surrounding region. The former addresses pre-slip behaviour by means of numerical simulation incorporating laboratory-derived friction laws, whereas the latter considers the statistical properties of micro-earthquakes. The former is orientated for long-term prediction. The latter is orientated for short-term prediction. Large earthquakes are generally associated with a "well-developed" fault system. The strength of the fault is perhaps very low as compared with the host rocks. As a result, large earthquakes often come with few fore-runners. Reliable prediction of such earthquakes relies on pre-slip behaviour. A well-developed fault, having the potential of large earthquakes, may lack of small-scale heterogeneities. As experimental results shown, a homogeneous fault is likely characterised by unclear nucleation 
leading to small and weak precursors. Following the development of observation technology, it will be possible in the future to catch small changes from the pre-slip movement with sufficient precision. However, we encounter another critical problem in that the final magnitude of an earthquake is perhaps determined by where and when the seismic slip stops rather than how much it has been slipped. As a result, short-term prediction of large earthquakes is both theoretically difficult and practically questionable.

In the laboratory, there are a number of mechanisms to speed up the occurrence as well as to stabilise the dynamic failure process. The possibility of being able to control the occurrence (including timing, size, and violence) of earthquakes in the crust through means of fluid injection is a valuable issue to be examined. Such research is meaningful not only for earthquake seismology but also for several industrial applications including EGS, shale gas, geological storage of $\mathrm{CO}_{2}$, fluid injection in gas and oil fields for enhanced oil/gas recovery (EOR/EGR) or dealing with unwanted water. In some applications such as EGS and shale gas production, hydrofracturing, by which earthquakes may be induced, is a necessary process. In other applications, fracturing is not required but is likely to occur. To be able to assess and control the maximum magnitude of induced earthquakes is an important issue that should be properly addressed. At the same time, insights gained from such applications could in turn shed light on earthquake seismology.

Acknowledgments We thank three anonymous reviewers for their insightful reviews and helpful comments to improve the paper. We wish to acknowledge financial support by the Japan Science Promotion Society (JSPS 21246134).

Open Access This article is distributed under the terms of the Creative Commons Attribution License which permits any use, distribution, and reproduction in any medium, provided the original author(s) and the source are credited.

\section{References}

Barenblatt G (1962) The mathematical theory of equilibrium crack in the brittle fracture. Adv Appl Mech 7:55-125

Benson PM, Thompson BD, Meredith PG, Vinciguerra S, Young RP (2007) Imaging slow failure in triaxially deformed Etna basalt using 3D acoustic-emission location and X-ray computed tomography. Geophys Res Lett 34(L03303):2006G. doi:10. 1029/L028721

Bjarnason ITh, Cowie P, Anders MH, Seeber L, Scholz CH (1993) The 1912 Iceland earthquake rupture: growth and development of a nascent transform system. Bull Seismol Soc Am 83:416-435

Blanpied ML, Lockner DA, Byerlee JD (1992) An earthquake mechanism based on rapid sealing of faults. Nature 358: 574-576. doi:10.1038/358574a0

Brown SR, Scholz CH (1985) Closure of Random Elastic Surfaces in Contact. J Geophys Res 90(B7):5531-5545
Byerlee JD, Lockner DA (1977) Acoustic emission during fluid injection into rock. In: Hardy HR, Leiton FW (eds) Proceedings of 1st conference on acoustic emission/microseismic activity in geological structures and materials, Trans Tech Publications, pp 87-98

Chester FM, Evans JP, Biegel RL (1993) Internal structure and weakening mechanisms of the San Andreas fault. J Geophys Res 98(B1):771-786

Cornet FH, Helm J, Poitrenaud H, Etchcopar A (1997) Seismic and aseismic slips induced by large-scale fluid injections. Pure appl Geophys 150:563-583

Cowie PA, Scholz CH (1992) Growth of faults by accumulation of seismic slip. J Geophys Res 97(B7):11085-11095

Cox SJD, Scholz CH (1988) Rupture initiation in shear fracture of rocks: an experimental study. J Geophy Res 93:3307-3320

Cox SJD, Scholz CH (1998) On the formation and growth of faults: an experimental study. J Struct Geol 10:413-430

Dieterich JH (1992) Earthquake nucleation on faults with rate- and state-dependent strength. In: Mikumo T, Aki K, Ohnaka M, Ruff Lj, Spudich PKP (eds) Earthquake source physics and earthquake precursors, vol 211. Tectonophysics, pp 115-134

Diodati P, Bak P, Marchesoni F (2000) Acoustic emission at the Stromboli volcano: scaling laws and seismic activity. Earth Planet Sci Lett 182:253-258

Dugdale D (1960) Yielding of steel sheets containing slits. J Mech Phys Sol 8:100-108

Engelder T (1974) Cataclasis and the generation of fault gouge. Geol Soc Am Bull 85:1515-1522

Fortin J, Stanchits G, Dresen G, Gueguen Y (2006) Acoustic emission and velocities associated with the formation of compaction bands in sandstone. J Geophys Res 111:B10203. doi:10.1029/ 2005JB003854

Fortin J, Stanchits S, Dresen G, Gueguen Y (2009) Acoustic emissions monitoring during inelastic deformation of porous sandstone: comparison of three modes of deformation. Pure appl Geophys 166:823-841. doi:10.1007/s00024-009-0479-0

Goebel TTW, Becker TW, Schorlemmer D, Stanchits S, Sammis C, Rybacki E, Dresen G (2012) Identifying fault heterogeneity through mapping spatial anomalies in acoustic emission statistics. J Geophys Res 117:B03310. doi:10.1029/2011JB008763

Granier T (1985) Origin, damping, and pattern of development of faults in granite. Tectonics 4(7):721-737

Gutenberg B, Richter CF (1954) Seismicity of the earth. Princeton Univ Press, Princeton

Hirata T (1987) Omori's power law aftershock sequences of microfracturing in rock fracture experiment. J Geophys Res 92:6215-6221

Hirata T, Satoh T, Ito K (1987) Fractal structure of spatial distribution of microfracturings. Geophys J Roy astr Soc 90:369-374

Ishida T, Aoyagi K, Niwa T, Chen Y, Murata S, Chen Q, Nakayama Y (2012) Acoustic emission monitoring of hydraulic fracturing laboratory experiment with supercritical and liquid $\mathrm{CO}_{2}$. Geophys Res Lett 39:L16309. doi:10.1029/2012GL052788

Jouniaux L, Masuda K, Lei X, Nishizawa O, Kusunose K, Liu L, Ma W (2001) Comparison of the microfracture localization in granite between fracturation and slip of a preexisting macroscopic healed joint by acoustic emission measurements. J Geophys Res 106:8687-8698

Kagan YY, Jackson DD (1991) Long-term earthquake clustering. Geophys J Int 104:117-133

Kanamori H (1977) The energy release in great earthquakes. J Geophys Res 82(20):2981-2987

Kato N, Yamamoto K, Hirasawa T (1994) Microfracture processes in the breakdown zone during dynamic shear rupture inferred from laboratory observation of near-fault high-frequency strong motion. Pure appl Geophys 142(3/4):713-734 
Kato N, Satoh T, Lei X, Yamamoto K, Hirasawa T (1999) Effect of fault bend on the rupture propagation process of stick-slip. Tectonophysics 310:81-99

Kawakata H, Cho A, Yanagidani T, Shimada M (1997) The observations of faulting in Westerly granite under triaxial compression by X-ray CT scan. Int $\mathrm{J}$ Rock Mech Min Sci Geomech Abstr 34:375

Kawakata H, Cho A, Yanagidani T, Shimada M (2000) Gross structure of a fault during its formation process in Westerly granite. Tectonophysics 323:61-76

Kerrich R (1986) Fluid infiltration into fault zones: chemical, isotopic, and mechanical effects. Pure Appl Geophy 124:225-268

Kranz RL, Satoh T, Nishizawa O, Kusunose K, Takahashi M, Masuda K, Hirata A (1990) Laboratory study of fluid pressure diffusion in rock using acoustic emissions. J Geophys Res 95(B13):21593-21607

Kurths J, Herzel H (1987) An attractor in a solar time series. Physica 25D:165-172

Kusunose K, Nishizawa O, Ito H, Ishida T, Hasegawa I (1982a) Source mechanism of acousticemission in rocks under uniaxial compression, Zisin. J Seism Soc Japan 34:241-250 (in Japanese)

Kusunose K, Nishizawa O, Onai K (1982b) AE gap in a rock under uniaxial compression, Zisin. J Seism Soc Japan 35:91-102 (in Japanese)

Kuwahara Y, Yamamoto K, Kosuga M, Hirasawa T (1985) Focal mechanisms of acoustic emissions in Abukumagranite under uniaxial and biaxial compressions. Sci Rep Tohoku Univ 5(30):1-14

Kwiatek G, Plenkers K, Nakatani M, Yabe Y, Dresen G, JAGUARSGroup (2010). Frequency-magnitude characteristics down to magnitude -4.4 for induced seismicity recorded at Mponeng Gold Mine, South Africa. Bull Seismol Soc Am 100(3): 1165-1173. doi:10.1785/0120090277

Laherrere J, Sornette D (1998) Stretched exponential distributions in nature and economy: "fat tails" with characteristic scales. Eur Phys J B 2:525-539

Lei X (2003) How do asperities fracture? An experimental study of unbroken asperities. Earth Planet Sci Lett 213:347-359

Lei X (2006) Typical phases of pre-failure damage in granitic rocks under differential compression. In: Cello G, Maramud BD (eds), Fractal analysis for natural hazards, vol 261. Geological Society, Special Publication, pp 11-29

Lei X (2012) Dragon-Kings in rock fracturing: insights gained from rock fracture tests in the laboratory. Eur Phys J Special Topics 205:217-230

Lei X, Satoh T (2007) Indicators of critical point behavior prior to rock failure inferred from pre-failure damage. Tectonophys 431:97-111

Lei X, Nishizawa O, Kusunose K, Satoh T (1992) Fractal structure of the hypocenter distribution and focal mechanism solutions of acoustic emission in two granites of different grain sizes. J Phys Earth 40:617-634

Lei X, Kusunose K, Nishizawa O, Cho A, Satoh T (2000a) On the spatio-temporal distribution of acoustic emission in two granitic rocks under triaxial compression: the role of pre-existing cracks. Geophys Res Lett 27:1997-2000

Lei X, Kusunose K, Rao MVMS, Nishizawa O, Satoh T (2000b) Quasi-static fault growth and cracking in homogeneous brittle rock under triaxial compression using acoustic emission monitoring. J Geophys Res 105:6127-6139

Lei X, Nishizawa O, Kusunose K, Cho A, Satoh T (2000c) Compressive failure of mudstone samples containing quartz veins using rapid $\mathrm{AE}$ monitoring: the role of asperities. Tectonophys 328:329-340

Lei X, Kusunose K, Satoh T, Nishizawa O (2003) The hierarchical rupture process of a fault: an experimental study. Phys Earth Planet Inter 137:213-228
Lei X, Masuda K, Nishizawa O, Jouniaux L, Liu L, Ma W, Satoh T (2004) Detailed analysis of acoustic emission activity during catastrophic fracture of faults in rock. J Struct Geol 26:247-258

Lei X, Yu G, Ma S, Wen X, Wang Q (2008) Earthquakes induced by water injection at $\sim 3 \mathrm{~km}$ depth within the Rongchang gas field, Chongqing, China. J Geophys Res 113:(B10310). doi:10.1029/ 2008JB005604

Lei X, Tamagawa T, Tezuka K, Takahashi M (2011) Role of drainage conditions in deformation and fracture of porous rocks under triaxial compression in the laboratory. Geophys Res Lett 38:L24310. doi:10.1029/2011GL049888

Lei X, Funatsu T, Villaescusa E (2013) Fault formation in foliated rock-insights gained from a laboratory study. In: Malovichko A, Malovichko D (eds) Proceedings of 8th international symposium on Rockbursts and Seismicity in Mines (RaSim8), Russia Saint-Peterburg-Moscow 2013, pp 41-49

Lloyd GE, Knipe RJ (1991) Deformation mechanisms accommodating faulting of quartzite under upper crustal condition. J Struct Geol 14:127-143

Lockner DA (1993) The role of acoustic emission in the study of rock fracture. Int J Rock Mech Min Sci Geomech Abstr 30:883-899

Lockner DA, Byerlee JD (1977) Acoustic emission and creep in rock at high confining pressure and differential stress. Bull Seismol Soc Am 67:247-258

Lockner DA, Byerlee JD (1980) Development of fracture planes during creep in granite. In: Hardy HR, Leiton FW (eds) Proceedings of 2 nd conference on acoustic emission/microseismic activity in geological structures and materials, Trans Tech Publications, pp 11-25

Lockner DA, Byerlee JD, Kuksenko V, Ponomarev A, Sidorin A (1991) Quasi-static fault growth and shear fracture energy. Nature 359:39-42

Lockner DA, Byerlee JD, Kuksenko V, Ponomarev A, Sidorin A (1992) Observation of quasistatic fault growth from acoustic emission. In: Evans B, Wong TF (eds) Fault mechanics and transport properties of rocks. Academic Press, New York, pp 3-31

Logan LM (1991) Strain distribution in fault zones and fluid flow. In: Proceedings of 2 nd annual international conference on high level radioactive waste management, pp 240-247

Ma S, Ma J, Liu L (2002) Experimental evidence for seismic nucleation phase. Chin Sci Bull 47(9):769-773

Maeda I (1979) On the recording and processing system for A.E.: application to a fracture experimentof marble, Zisin. J Seism Soc Japan 32:233-241 (in Japanese)

Main IG, Meredith PG (1991) Stress corrosion constitutive laws as a possible mechanism of intermediate-term and short-term seismic quiescence. Geophys J Int 107:363-372

Main IG, Meredith PG, Jones C (1989) A reinterpretation of the precursory seismic $b$ value anomaly from fracture mechanics. Geophys J 96:131-138

Main IG, Meredith PG, Sammonds PR (1992) Temporal variations in seismic event rate and b-values from stress corrosion constitutive laws. Tectonophysics 211:233-246

Main IG, Sammonds PR, Meredith PG (1993) Application of a modified Griffith criterion to the evolution of fractal damage during compressional rock failure. Geophys J Int 115:367-380

Mair K, Marone C, Young PR (2007) Rate dependence of acoustic emissions generated during shear of simulated fault gouge. Bull Seismol Soc Am 97(6):1841-1849

Manthei G (2005) Characterization of acoustic emission sources in a rocksalt specimen under triaxial compression. Bull Seismol Soc Am 95:1674-1700

Masuda K, Mizutani H, Yamada I (1987) Experimental study of strain-rate dependence and pressure dependence of failure properties of granite. J Phys Earth 35:37-66 
Masuda K, Mizutani H, Yamada I (1988) Effects of water on timedependent behavior of granite. J Phys Earth 36:291-313

Masuda K, Nishizawa O, Kusunose K, Satoh T, Takahashi M, Kranz RL (1990) Positive feedback fracture process induced by nonuniform high-pressure water flow in dilatant granite. J Geophys Res 95(B13):21583-21592

Mayr SI, Stanchits S, Langenbruch C, Dresen G, Shapiro SA (2011) Acoustic emission induced by pore-pressure changes in sandstone samples. Geophysics 76. doi:10.1190/1.3569579

McLaskey, GC, Lockner DA (2014) Preslip and cascade processes initiating laboratory stick slip. J Geophys Res Solid Earth 119. doi:10.1002/2014JB011220

Meredith PG, Main I, Jones C (1990) Temporal variations in seismicity during quasi-static and dynamic rock failure. Tectonophysics 175:249-268

Mogi K (1962) Study of elastic shocks caused by the fracture of heterogeneous materials and its relation to earthquake phenomena. Bull Earthq Res Inst 40:125-173

Mogi K (1968) Source locations of elastic shocks in the fracturing process in rocks (1). Bull Earthq Res Inst 46:1103-1125

Moura A, Lei X, Nishizawa O (2005) Prediction scheme for the catastrophic failure of highly loaded brittle materials or rocks. J Mech Phys Solids 53:2435-2455

Moura A, Lei X, Nishizawa O (2006) Self-similarity in rock cracking and related complex critical exponents. J Mech Phys Solids 54:2544-2553

Nishizawa O, Noro H (1990) A self-exciting process of acoustic emission occurrence in steady creep of granite under uniaxial stress. Geophys Res Lett 17:1521-1524

Nishizawa O, KusunoseK Yanagidani T, Oguchi F, Ehara S (1982) Stochastic process of the occurrence of $\mathrm{AE}$ events and hypocenter distributions during creep in Ohshima granite, Zisin. J Seism Soc Japan 35:117-132 (in Japanese)

Nishizawa O, Onai K, Kusunose K (1984/1985) Hypocenter distribution and focal mechanism of $\mathrm{AE}$ events during two stress stage creep in Yugawara andesite. Pure Appl Geophys 122:36-52

Ohnaka M, Mogi K (1981) Frequency dependence of acoustic emission activity in rocks under incremental uniaxial compression. Bull Earthq Res Inst 56:67-89

Ohnaka M, Mogi K (1982) Frequency characteristics of acoustic emission in rocks under uniaxial compression and its relation to the fracturing process to failure. J Geophys Res 87:3873-3884

Ojala IO, Main IG, Ngwenya BT (2004) Strain rate and temperature dependence of Omori law scaling constants of $\mathrm{AE}$ data: implications for earthquake foreshock-aftershock sequences. Geophys Res Lett 31:L24617. doi:10.1029/2004GL020781

Ouillon G, Castaing C, Sornette D (1996) Hierarchical geometry of faulting. J Geophys Res 101(B3):5477-5487

Ponomarev AV, Zavyalov AD, Smirnov VB, Lockner DA (1997) Physical modeling of the formation and evolution of seismically active fault zones. Tectonophysics 277:57-81

Rao MVMS, Lakshmi KJ, Rao GM, Vijayakumar K, Udayakumar S (2011) Precursory microcracking and brittle failure of Latur basalt and migmatite gneiss under compressive loading. Curr Sci 101:1053-1059

Reches Z, Lockner DA (1994) Nucleation and growth of faults in brittle rocks. J Geophys Res 99:18159-18173

Rice JR (1983) Constitutive relations for fault slip and earthquake instabilities. Pure appl Geophys 121(3):443-475

Rice JR, Cocco M (2007) Seismic fault rheology and earthquake dynamics. In: Handy MR, Hirth G, Hovius N (eds) Tectonic faults: agents of change on a dynamic earth. Dahlem Workshop 95, Berlin, January 2005 on the Dynamics of Fault Zones, MIT Press, Cambridge, pp 99-137

Sammonds P, Ohnaka M (1998) Evolution of microseismicity during frictional sliding. Geophys Res Lett 25(5):699-702
Sano O, Ito I, Terada M (1981) Influence of strain rate on dilatancy and strength of Oshima granite under uniaxial compression. J Geophys Res 86:9299-9311

Sano O, Terada M, Ehara S (1982) A study on the time-dependent microfracturing and strength of Oshima granite. Tectonophys $84: 343-362$

Satoh T, Idehara O, Nishizawa O, Kuseunose K (1986) Hypocenter distribution and focal mechanisms of $\mathrm{AE}$ events under triaxial compression-focal mechanisms of $\mathrm{AE}$ events in Yugawara andesite-, Zisin. J Seism Soc Japan 39:351-360 (in Japanese)

Satoh T, Nishizawa O, Kusunose K (1990) Fault development in Oshima granite under triaxial compression inferred from hypocenter distribution and focal mechanism of acoustic emission. Sci Rep Tohoku Univ 5(33):241-250

Satoh T, Shivakumar K, Nishizawa O, Kusunose K (1996) Precursory localization and development of microfractures along the ultimate fracture plane in amphibolite under triaxial creep. Geophys Res Lett 23:865-868

Satoh T, Nishizawa O, Kusunose K (2000) Focal mechanisms of acoustic emission in Oshima granite under triaxial compression. Sci Rep Tohoku Univ 5(35):121-131

Scholz CH (1968a) Experimental study of the fracturing process in brittle rock. J Geophys Res 73:1447-1454

Scholz CH (1968b) The frequency-magnitude relation of microfracturing and its relation to earthquakes. Bull Seismol Soc Am 58:399-417

Scholz CH (1968c) Microfracturing and in elastic deformation of rock. J Geophys Res 7(3):1417-1432

Scholz CH, Anders MH (1994) The permeability of faults. In: The mechanical involvement of fluids in faulting: US Geological Survey Open-File Report 94-228, pp 247-253

Scholz CH, Dawers NH, Yu JZ, Anders MH (1993) Fault growth and fault scaling laws: preliminary results. J Geophys Res 98: 21951-21961

Schubnel A, Thompson BD, Fortin J, Gueguen Y, Young RP (2007) Fluid-induced rupture experiment on Fontainebleau sandstone: premonitory activity, rupture propagation, and aftershocks. Geophys Res Lett 34:L19307. doi:10.1029/2007GL031076

Sellers EJ, Kataka MO, Linzer LM (2003) Source parameters of acoustic events and scaling with mining-induced seismicity. J Geophys Res 108(B9):2418

Shamina OG (1987) Source mechanisms of acoustic emissions produced by the fracturing of granite block. Izv Acad Sci Phys Solid Earth 23:707-711

Sibson RH (1981) Fluid flow accompanying faulting: field evidence and models. In: Simpson DW, Richards PG (eds) Earthquake prediction: an international review, Am Geophys Union Maurics Ewing, vol 4, pp 593-403

Sleep NH, Blanpied M (1992) Creep, compaction, and the weak rheology of major faults. Nature 359:687-692

Sondergerd CH, Estey L (1981) Acoustic emission study of microfracturing during the cyclic loading of Westerly granite. J Geophys Res 86:2915-2924

Sondergerd CH, Estey L (1982) Source mechanism and microfracturing during uniaxial cycling of rock. Pure appl Geophys 120: $151-166$

Sornette A, Sornette D (1990) Earthquake rupture as a critical point, consequences for telluric precursors. Tectonophysics 179: 327-334

Stanchits S, Vinciguerra S, Dresen G (2006) Ultrasonic velocities, acoustic emission characteristics and crack damage of basalt and granite. Pure appl Geophys 163:974-993

Stanchits S, Fortin J, Gueguen Y, Dresen G (2009) Initiation and propagation of compaction bands in dry and wet Bentheim sandstone. Pure appl Geophys 166:843-868. doi:10.1007/s00024009-0478-1 
Sun X, Hardy HR, Rao MVMS (1991) Acoustic emission monitoring and analysis procedures utilized during deformation studies on geologic materials, In: Sachse W, Roget J, Yamaguchi K (eds) Acoustic emission: current practice and future directions. ASTM Special Technical Publication, pp 365-380

Thompson BD, Young PR, Lockner DA (2005) Observations of premonitory acoustic emission and slip nucleation during a stick slip experiment in smooth faulted Westerly granite. Geophys Res Lett 32:L10304. doi:10.1029/2005GL022750

Thompson BD, Young RP, Lockner DA (2006) Fracture in Westerly granite under $\mathrm{AE}$ feedback and constant strain rate loading: nucleation, quasi-static propagation, and the transition to unstable fracture propagation. Pure appl Geophys 163:995-1019

Thompson BD, Young RP, Lockner DA (2009) Premonitory acoustic emissions and stick-slip in natural and smooth-faulted Westerly granite. J Geophys Res 114:B02205. doi:10.1029/2008JB005753

Utsu T (1961) A statistica study on the occurrence of after shocks. Geophys Mag 30:521-605

Utsu T, Ogata Y, Matsu'ura RS (1995) The Centenary of the Omori formula for a decay law of aftershock activity. J Phys Earth 43:1-133

Vermilye JM, Scholz CH (1998) The process zone: a microstructural view of fault growth. J Geophys Res 103(B6):12223-12237

Villaescusa E, Lei X, Nishizawa O, Funatsu T (2009) Laboratory testing of brittle intact rock-implications for in situ stress measurements and rock mass failure. Proceed 2009 Austra Min Technol Conf, pp 27-28

Wang L, Ma S, Ma L (2008) Accelerating moment release of acoustic emission during rock deformation in the laboratory. Pure appl Geophys 165:181-199. doi:10.1007/s00024-008-0305-0

Weeks J, Lockner D, Byerlee J (1978) Change in b-value during movement on cut surfaces in granite. Bull Seismol Soc Am 68(2):333-341
Wong TF (1985) Effects of pressure on the micromechanics of faulting in San Marcos gabbro. J Struct Geol 7(6):737-749

Yabe Y (2008) Evolution of source characteristics of AE events during frictional sliding. Earth Planets Space E-Lett 60:e5-e8

Yabe Y, Kato N, Yamamoto K, Hirosawa T (2003) Effect of sliding rate on the activity of acoustic emission during stable sliding. Pure appl Geophys 160:1163-1189

Yamashita T, Knopoff L (1989) A model of foreshock occurrence. Geophys J 96:389-399

Yanagidani T, Ehara S, Nishizawa O, Kusunose K, Terada M (1985) Localization of dilatancy in Oshima granite under constant uniaxial stress. J Geophys Res 90:6840-6858

Yin XC, Yu HZ, Kukshenko V, Xu ZY, Wu ZS, Li M, Peng KY, Elizarov S, Li Q (2004) Load-unload response ratio (LURR), accelerating moment/energy release (AM/ER) and state vector saltation as precursors to failure of rock specimens. Pure appl Geophys 161:2405-2416

Young RP, Collins DS (2001) Seismic studies of rock fracture at the Underground Research Laboratory, Canada. Int J Rock Mach Min Sci 38:787-799

Yu HZ, Yin XC, Xia MF, Xu ZY, Li M, Liang NG, Peng KY, Victor K, Wu ZS, Li Q, Surguei E (2004) Experimental research on critical point hypothesis. Acta Seismol Sin 17:129-137

Zang A, Wagner FC, Stanchits S, Dresen G, Andresen R, Haidekker MA (1998) Source analysis of acoustic emissions in Aue granite cores under symmetric and asymmetric compressive loads. Geophys J Inter 135(3):1113-1130. doi:10.1046/j.1365-246X. 1998.00706.x

Zang A, Wagner FC, Stanchits S, Janssen C, Dresen G (2000) Fracture process zone in granite. J Geophys Res 105:23651-23661

Zhao Y (1998) Crack pattern evolution and a fractal damage constitutive model for rock. Int J Rock Mech Min Sci 35: 349-366 